\title{
Decentralisation and urban primary health services: a case study of Delhi's Mohalla Clinics
}

\section{Commonwealth Journal of Local Governance}

Issue 23: 2020

http://epress.lib.uts.edu.au/ojs/index.php/cjlg

\section{Sejal Patel}

Faculty of Planning

CEPT University

Ahmedabad

380009

India

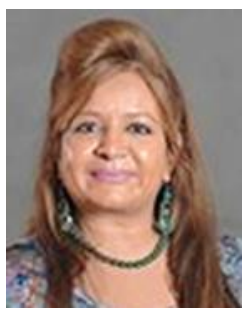

Email: sejal@cept.ac.in.

\section{Priyankita Pant}

Faculty of Planning CEPT University

Ahmedabad

380009

India

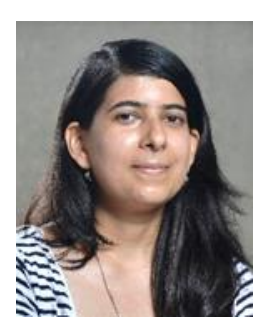

Email: priyankita.pant@cept.ac.in

\begin{abstract}
The Indian political party Aam Aadmi, which assumed power in the city-state of Delhi in 2015, introduced Mohalla Clinics (i.e. neighbourhood clinics) to provide free primary health services for all, as a response to the rising inaccessibility of primary healthcare facilities for the urban poor. These clinics were to be governed through Mohalla Sabhas (i.e. neighbourhood committees), which are instruments of participatory governance within the neighbourhood. The research compares promises and practice for Mohalla Clinics, especially focusing on governance and the politics surrounding it. The authors find that in their current form Mohalla Clinics are limited to providing primary curative healthcare and have shown limited success, although Mohalla Clinic users do save time and expenditure on primary healthcare, and the clinics have led to a more comprehensive form of primary healthcare than in the past. However, Mohalla Clinics are governed in a top-down fashion by the Government of the National Capital Territory-Delhi, and not by urban local bodies or the envisaged neighbourhood committees. As a result, they face problems that may inhibit their functioning in the long term.
\end{abstract}

Keywords: Participatory urban governance, urban primary health services, urban poor, social infrastructure, New Delhi, Mohalla Sabhas, Mohalla Clinics 


\section{Introduction}

Cities arguably have a wider range of health and social infrastructure than rural areas. However, for countries in the global south, access to these services for the urban poor may be restricted by their inability to pay (e.g. for medication and supplies, even if health services are free), inconvenient locations or times of operation, or poor quality of healthcare services. All of these can result in low utilisation of even the most basic preventative and curative health services (WHO 2010). With rapid urbanisation, the urban poor population is also increasing rapidly. This group, in India, suffers from poor health: for example, the mortality rate (per 1,000 live births) for under-fives at 59.3 is significantly higher than the urban average of 34.4 (IIPS and ICF 2017). Consumer expenditure data shows that urban households spend $5 \%$ to $6 \%$ of their total expenditure on health, with half of this spending on primary healthcare alone (Ministry of Health and Family Welfare 2013). Whereas in rural areas it is a lack of proper medical practitioners that limits access to healthcare, in urban areas it is cost. These realities led to the National Urban Health Mission (NUHM) being launched in 2013 as India's first exclusive urban health mission, and its remit has been extended till 2020. In 2020 this has been subsumed under Pradhan Mantri - Atmanirbhar Swasth Bharat Yojana (PMASBY; meaning prime minister's self-reliant healthy India scheme), a new scheme created in the wake of the global Covid-19 pandemic for pandemic preparedness and management. These schemes are applicable in Delhi though they are not in convergence with Delhi's health schemes. Another scheme called Pradhan Mantri Jan Arogya Yojana (PMJAY), or the prime minister's public health scheme, was launched in 2018. It addresses the healthcare needs of the poor in both rural and urban areas through the provision of health insurance of Indian Rupees (INR) 500,000 (USD 6,791) ${ }^{1}$ per family for secondary and tertiary care. This scheme, however, is not applicable in the city-state of Delhi as its healthcare schemes are incompatible with the insurance model of PMJAY. Also, PMJAY only covers the cost of hospitalisation and not primary healthcare.

The Government of National Capital Territory-Delhi (GoNCT-D) launched 'Mohalla Clinics' (i.e. neighbourhood clinics) in 2015, which aim to provide primary healthcare for free at a neighbourhood level, thereby making it more accessible. GoNCT-D also raised healthcare higher up the political agenda, including by shifting the political discourse away from physical infrastructure and towards social infrastructure (Lahariya 2017). This paper aims to understand the promises vs. the practices of Mohalla Clinics in providing the people of Delhi with primary urban healthcare, with particular emphasis on their governance and the politics surrounding it.

\footnotetext{
${ }^{1}$ As per currency exchange rate from xe currency dated $19^{\text {th }}$ December 2020 https://www.xe.com/currencyconverter/convert/?Amount=500000andFrom=INRandTo=USD
} 


\section{Need for primary healthcare}

The World Health Organization (WHO) declaration at Alma Alta in 1978, which India is a signatory to, emphasised the importance of primary healthcare. "Primary healthcare [should] address the main health problems in the community, providing promotive, preventive, curative and rehabilitative services accordingly" (emphasis added) (WHO 1978, p. 2). However, this has not been the trajectory of primary healthcare in India over the past 40 years, which instead has featured vertical health programmes focusing on single diseases, despite various policies stating otherwise, and on tackling health issues one at a time rather than looking at overall health comprehensively (Nundy 2005). India's expenditure on healthcare in 2015 is $3.89 \%$ of GDP, which is arguably low compared to other BRICS ${ }^{2}$ nations - e.g. South Africa at $8.20 \%$ and Brazil at $8.91 \%$ in the same year (WHO n.d.). If we compare budget trends, there has been only a moderate increase in the funds allocated in the union budget, ${ }^{3}$ such that when adjusted for inflation the situation can be viewed as virtual stagnation (Sundararaman et al. 2016).

\section{Community participation in health}

Community participation is one of the key principles of Mohalla Clinics - along with accessibility, equity, an assured package of essential health services and defined quality standards for services (Lahariya 2017). The concept of community participation in primary health was formally introduced at the Alma Ata conference in 1978 and has been explored in detail in various studies. Rifkin (1986) reviewed 200 global case studies over a decade (1976-1986) and drew the following lessons:

1. there is no universally accepted definition of community participation;

2. health services alone will not lead to community participation; rather a community participation framework should already exist, and health should be one of its components;

3. a 'one model fits all' approach should not be used; and

4. it is not possible to consider community participation in isolation from its political context.

The present study discusses how community participation operates in practice in Mohalla Clinics, using a framework provided by Rifkin (1986) which is depicted in Figure 1. Since healthcare, particularly in its diagnostic and curative aspects, is a technical subject, and given the context in which Mohalla Clinics operate (i.e. mainly for the urban poor), the study focuses on whether community participation - for example in deciding the location and spatial distribution of clinics and their operating hours - can help improve the efficiency of their implementation.

\footnotetext{
${ }^{2}$ BRICS is an acronym associated with the nations Brazil, Russia, India, China and South Africa which are said to be major emerging national economies.

${ }^{3}$ Union Budget (of India) is an annual account of finances, a statement of estimated receipts and expenditure of Government of India.
} 
Figure 1: Community participation in healthcare programmes

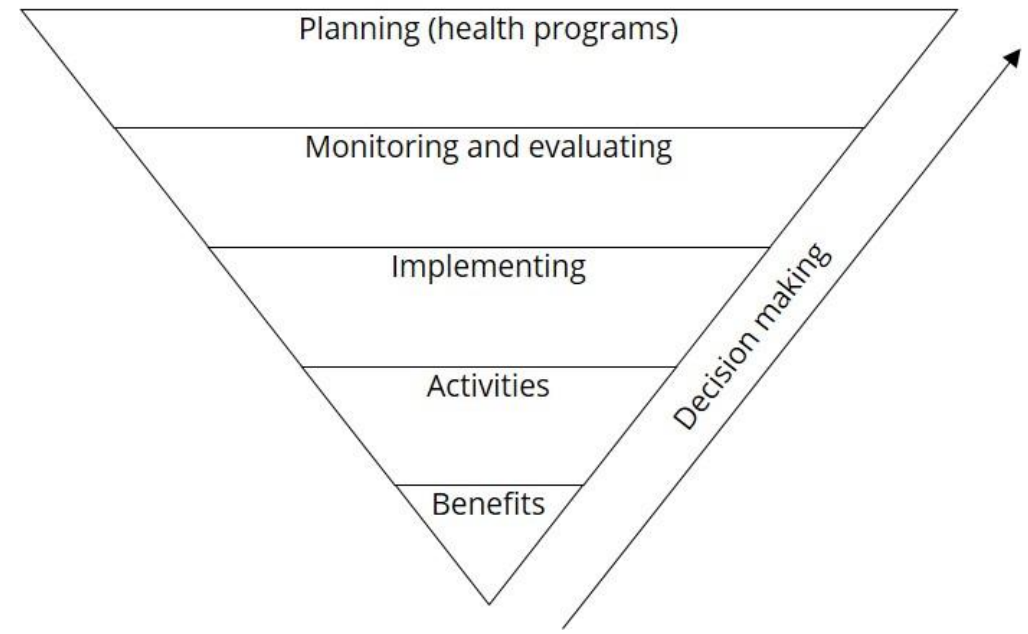

Source: Rifkin (1986, p. 247)

\section{Literature review: history of participation and participatory governance}

Participation as an approach to policy-making, governance and project implementation is popular in both developing and developed countries (Hickey and Mohan 2004). The first attempt to classify levels of citizen participation and 'nonparticipation' was by Arnstein (1969), through an eight-rung ladder ranging from citizen control on the highest rung to 'manipulation' on the lowest rung (Figure 2).

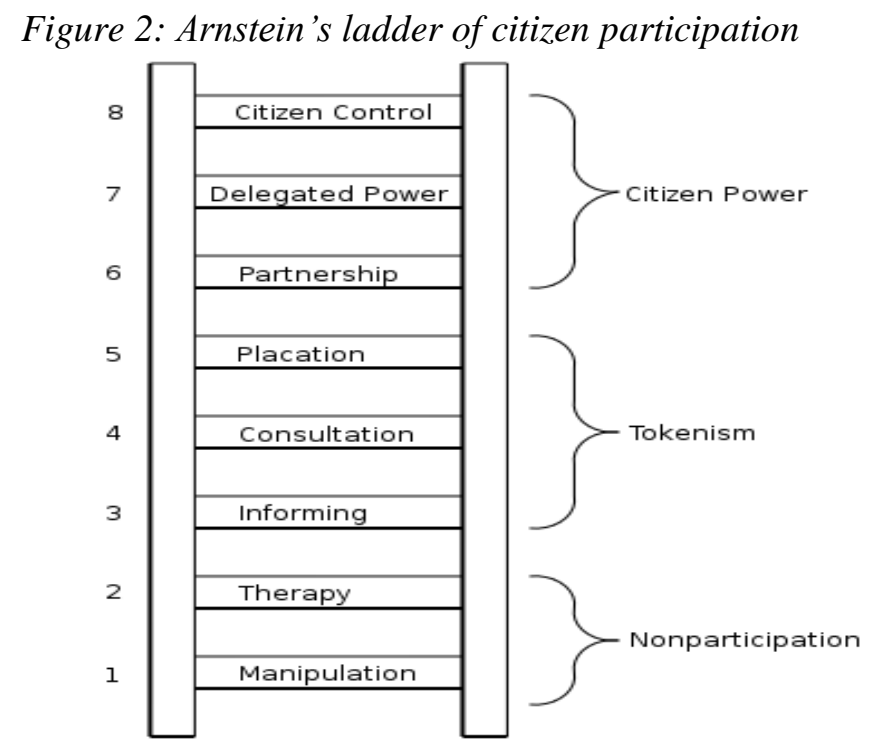

Source: Arnstein (1969, p. 217)

Citizen participation evolved into community participation as its context changed - from citizen participation in 1960s government schemes in developed nations to community participation in the neoliberal era in underdeveloped or developing nations (Arnstein 1969; Choguill 1996). Whereas 'manipulation' was the lowest rung in Arnstein's ladder, Choguill's ladder (1996), shown in Figure 3, breaks down community participation somewhat differently - for example including 'conspiracy' and 'self-management' as two other rungs, as these are prevalent in developing nations. Manipulation is 
also explored further by drawing out its types: dissimulation, diplomacy and informing. Community empowerment, rather than citizen control, is at the top. It is noteworthy that Choguill's ladder focuses more on the process of development than does Arnstein's ladder.

Figure 3: Choguill's ladder of community participation

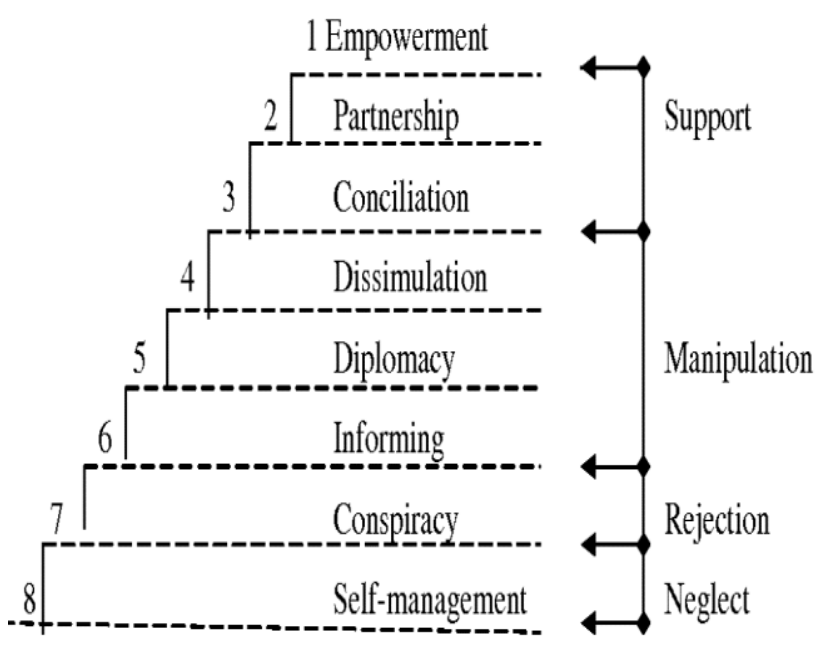

Source: Choguill (1996, p. 442)

In the globalisation era, decentralisation and neoliberalisation are two sides of the same global restructuring process and are usually simultaneously launched in urban governance. While neoliberalisation heralds policies towards market-oriented economic growth, decentralisation or participatory governance purports to offer opportunities to those without exchange entitlements to participate in decision-making processes in urban governance and thereby seek rights to improve their well-being (Purcell 2003; Goodwin and Painter 1996; Patel et al. 2016a). Hence new spaces and opportunities have emerged for citizen engagement in policy formation. There are policy instruments, legal frameworks and programmes that promote citizen participation. However, it is also becoming apparent that merely creating new institutional arrangements does not necessarily result in greater inclusion or pro-poor policy change, despite the prevalent assumptions. The critical question is where power truly lies, and this can be assessed through mapping onto the 'power cube', which is a framework for investigating the spaces, places and forms of power, and their inter-relationship (Gaventa 2006). The three levels of governments operating in Delhi with no clear demarcation of their roles and responsibilities, explained in the next section, can be best assessed through Gaventa's power cube.

Visually presented as a cube (Figure 4), in the model, each side represents a dimension or set of relationships, not a fixed or static set of categories. 
Figure 4: Gaventa's power cube visualised

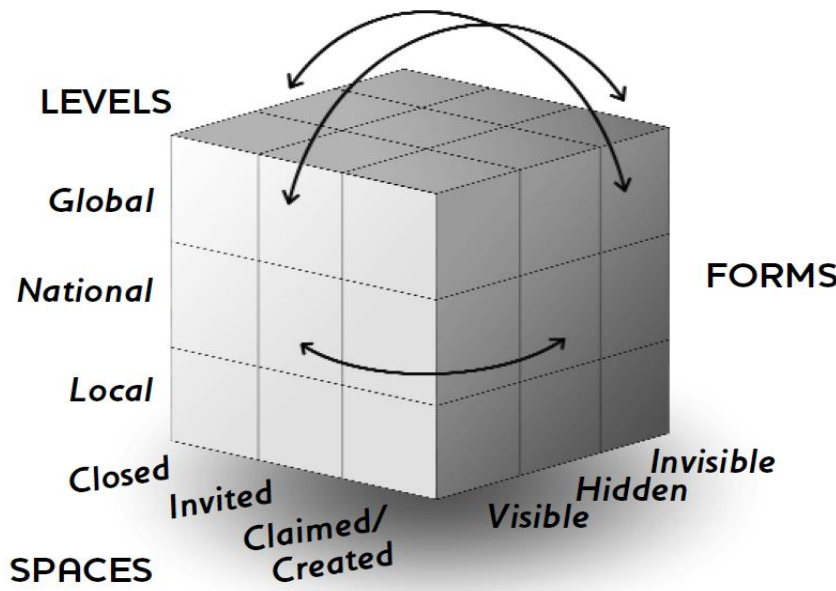

Source: Gaventa (2006, p. 25)

Firstly, power may be exercised at local, national or global levels. Secondly, the forms that power take have been defined as visible, hidden and invisible. Visible forms of power are contests over interests that are visible in public spaces like legislatures, local assemblies which are bound by formal rules, structures, authorities and procedures for decision-making (VeneKlasen et al. 2002; Gaventa 2006). Hidden forms of power are used by certain power players to maintain their power and privilege by creating obstructions to people's participation or by gatekeeping over the facts to be brought forward (VeneKlasen et al. 2002; Gaventa 2006). Invisible power goes one step further: it involves dominant groups continuing to hold power by keeping vulnerable groups unaware of their rights, for example by manipulating the narrative of how the powerless groups perceive themselves, so they feel unable to change and therefore accept the status quo (VeneKlasen et al. 2002; Gaventa 2006).

Thirdly, spaces to exercise power may be closed, invited or claimed. Closed spaces are where powerholders or authorities such as politicians, bureaucrats, professionals, executives make decisions with little broad consultation or involvement of the ordinary people (Gaventa 2006). Invited spaces are those where the people as users, beneficiaries or citizens are invited to participate by various kinds of power players; not necessarily government, but also international agencies or non-governmental organisations. Claimed spaces are carved out by less powerful actors from within the spaces available to the powerholders through social movements or community mobilisation for an issue (Cornwall 2002; Gaventa 2006).

\section{Governance framework in Delhi}

Delhi is a city-state in India, with a population of 16.8 million in 2011 and an area of 1,483 square kilometres $\left(\mathrm{km}^{2}\right)$ and nearly 1.8 million or $11 \%$ of the population are living in slums (Registrar General and Census Commissioner of India 2011). The National Accounts Division, Ministry of Statistics and Programme Implementation, Government of India (GoI) estimates that in 2021 the population of Delhi will reach 20 million. 
The governance framework in Delhi is different from other Indian cities. India has three levels of government - the union government (which is the central government/GoI), state level governments and local (sub-state level) governments. The Constitution of India lays out the functions and powers of each level of government, including state level legislation relating to public health, sanitation, hospitals and dispensaries, under the Constitution's seventh schedule and local government level responsibilities on public health and sanitation under the twelfth schedule. The state government also has control over the local governments. Most cities are governed by these three levels, except in union territories ${ }^{4}$ which are directly governed by GoI and the respective Urban Local Bodies (ULBs). There are 28 states and seven union territories in India.

Delhi was a union territory from 1956 to 1992 , governed directly by the GoI with no legislative assembly. However, in 1992 the Government of National Capital Territory of Delhi Act 1991 came into force, leading to the formation of GoNCT-D. GoNCT-D has a legislative assembly of 70 members who have the power to make laws for National Capital Territory (NCT) of Delhi matters as set out in the state list or the concurrent list of the Constitution of India (just like other Indian states). However, it does not have the power to make laws relating to land, police or public order, and these areas remain under the jurisdiction of the parliament of India. For these functions, GoNCT-D has no say even in matters of execution (Sheikh and Banda 2015). Those governance functions in Delhi which are vested with the GoI are headed by the lieutenant governor of Delhi, appointed by the president of India, who leads the executive bodies that carry out the functions regulating land, the police and public order. The Delhi Development Authority (DDA) is responsible for all spatial planning, land development and housing in Delhi. The DDA was created in 1957, when Delhi was a union territory and still, despite the establishment of GoNCT-D in 1992, continues to be accountable to the Ministry of Housing and Urban Affairs, GoI (Sheikh and Banda 2015). GoNCT-D, meanwhile, manages transport, industrial development, revenue administration, power generation, food and civil supplies, and health and family welfare.

There are five ULBs in Delhi: the North Delhi Municipal Corporation, the South Delhi Municipal Corporation, the East Delhi Municipal Corporation, the New Delhi Municipal Council (NDMC), and the Cantonment Board (CB) (see Figure 5). The members of the governing bodies of the last two, NDMC and $\mathrm{CB}$, are nominated by GoI and not elected by the people. In the first three, elections are held: North Delhi Municipal Corporation has 104 wards; South Delhi Municipal Corporation has 104 wards; East Delhi Municipal Corporation has 64 wards. Each ward holds an average population of 60,000 (GoNCT-D 2016). The three municipal corporations were a single entity until 2012, called the Municipal Corporation of Delhi (MCD). MCD was established under the Municipal Corporation of

\footnotetext{
${ }^{4}$ In India union territories are a type of administrative division which are directly governed by the union government, unlike states which have a second tier of government i.e. the state government.
} 
Delhi Act 1957. In 1993 this Act was amended in accordance with the 74th Constitutional Amendment Act $\left(74^{\text {th }}\right.$ CAA). The body was trifurcated through the Municipal Corporation of Delhi (Amendment) Act 2011. The power to appoint the municipal commissioner for these corporations rests with the union government. In other states, it rests with the state government. Therefore GoI has a substantial hold on the three Municipal Corporations in Delhi (MCDs).

\section{Figure 5: Urban local bodies in Delhi}

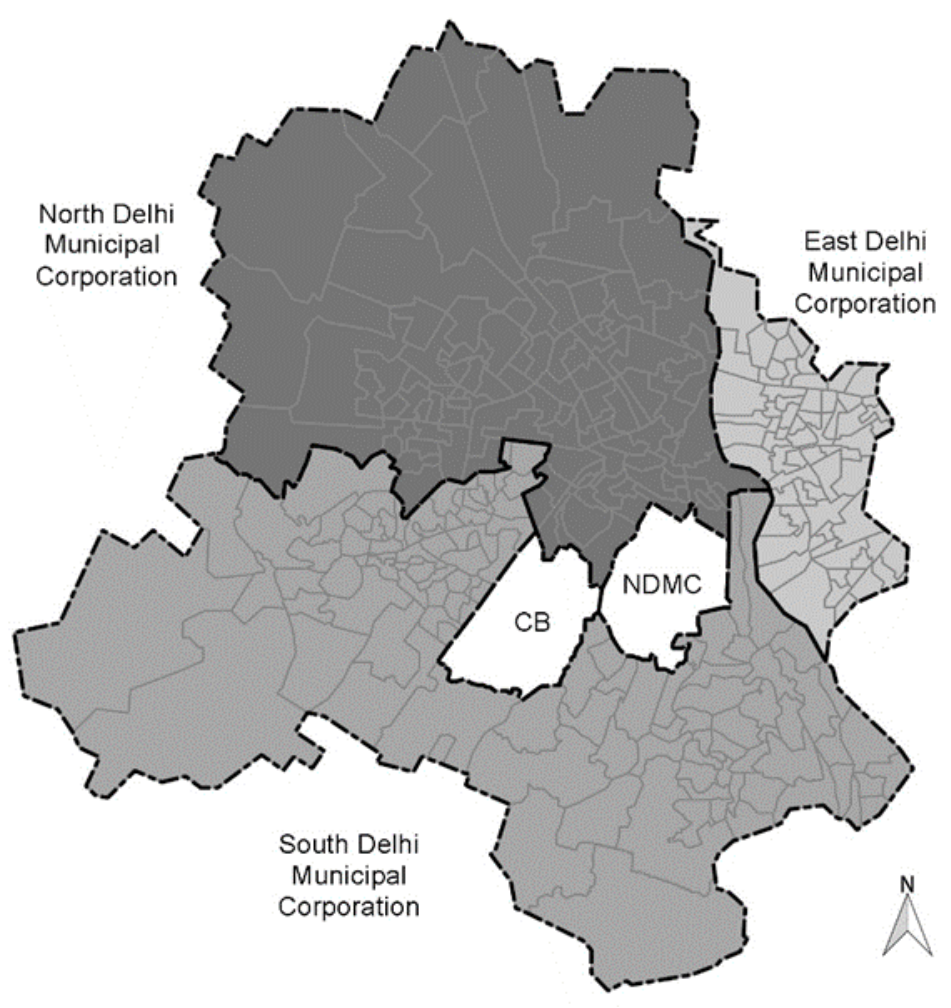

Source: Data from Delhi Election Commission; compiled by authors

The three levels of government - union, NCT and local - have complex and overlapping roles and functions (Rao 2016). The situation is further complicated by different political parties in power at different levels of government. In 2019, at the time of conducting this research, the right-wing nationalist Bhartiya Janta Party (BJP) was in power in the union government and the three ULBs, while the Aam Aadmi Party (AAP) was in power at the NCT. The various agencies under GoI, GoNCT-D, and the ULBs working under various functional heads, are illustrated in Figure 6 as conceptualised by Rao (2016). Even this structure, however, does not capture the full complexity of Delhi's governance arrangements, and Rao herself notes that it is "misleading because activities within functional heads always involve other agencies and also because some agencies wield more de facto power [than others]" (Rao 2016, p. 11). This complexity can also be seen in public health sector governance. 
Figure 6: Broad mapping of functional areas across Delhi's agencies and departments

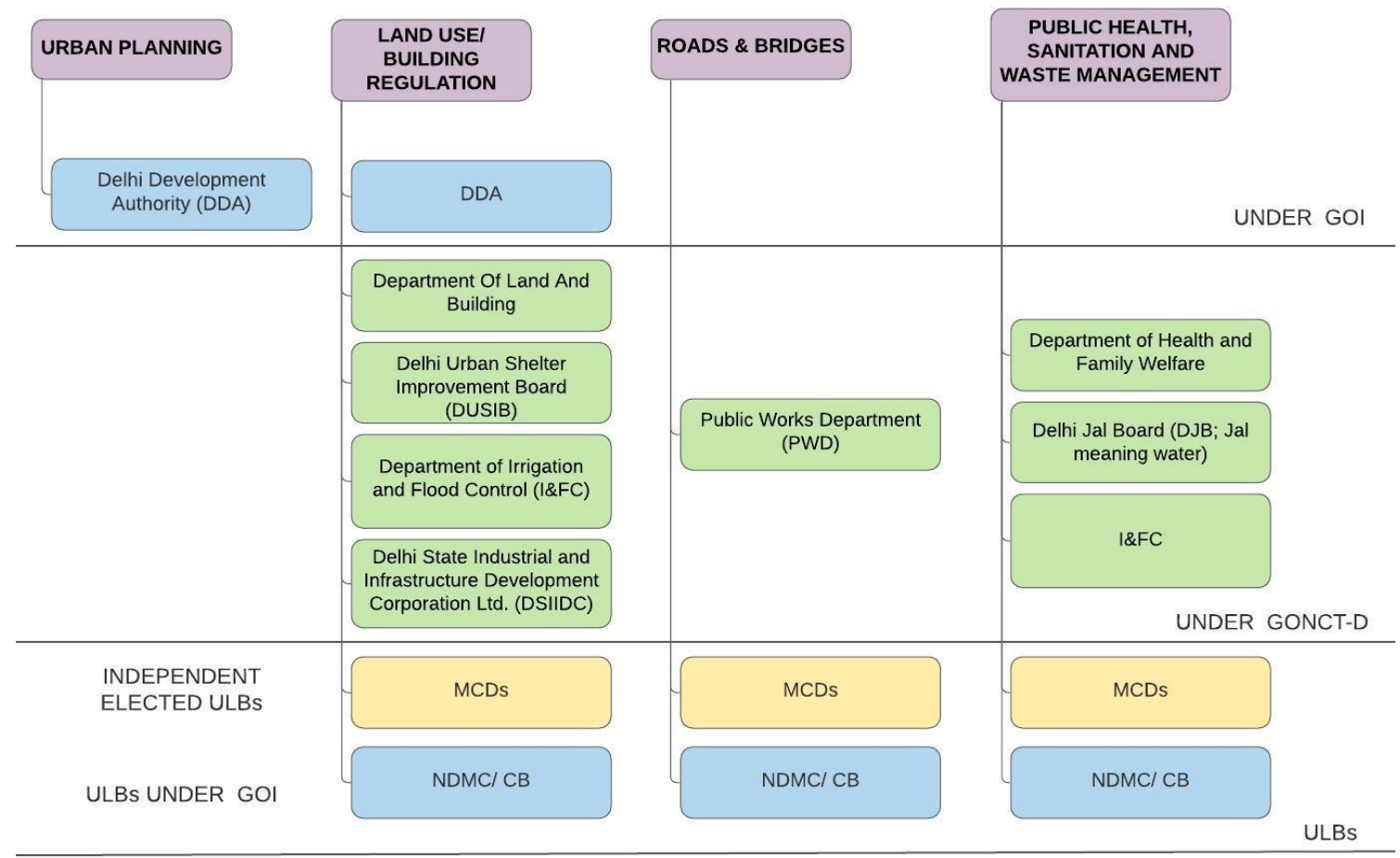

Source: Rao (2016), adapted by authors

\section{Public health facilities in Delhi}

Public healthcare in Delhi is provided mainly by GoNCT-D and local bodies, with some involvement from autonomous institutions and GoI. The DDA (2007) prepared the Master Plan of Delhi 2021 (MPD 2021) which has proposed a hierarchy of health services and their hinterland populations as part of suggested planning norms and standards, shown in Table 1.

Table 1: Planning norms and standards for health services in Delhi

\begin{tabular}{|r|l|c|c|}
\hline \multicolumn{1}{|c|}{$\begin{array}{c}\text { nr } \\
\text { no }\end{array}$} & \multicolumn{1}{|c|}{ Category } & Population/unit & Plot area (approx) \\
\hline 1 & Hospital type A (501 beds and above) & 500,000 & 2.5 to 4.0 Hectare (ha) \\
\hline 2 & Hospital type B (201-500 beds) & 250,000 & 1.5 to 2.5 ha \\
\hline 3 & Hospital type C (101-200 beds) & 100,000 & 0.5 to 1.5 ha \\
\hline 4 & Hospital type D (up to 100 beds) & 100,000 & 0.25 to 0.5 ha \\
\hline 5 & Other health facilities & & \\
& a $\quad$ i) Maternity home & 50,000 & $1,000 \mathrm{~m}^{2}$ to 2,000 square metre $\left(\mathrm{m}^{2}\right)$ \\
& & 50,000 & $1,000 \mathrm{~m}^{2}$ to $2,000 \mathrm{~m}^{2}$ \\
& ii) Nursing home/Polyclinic & 10,000 & $800 \mathrm{~m}^{2}$ to $1,200 \mathrm{~m}^{2}$ \\
& bi) Dispensary & 50,000 & $500 \mathrm{~m}^{2}$ to $800 \mathrm{~m}^{2}$ \\
& i) Family welfare centre & 50,000 & $500 \mathrm{~m}^{2}$ to $800 \mathrm{~m}^{2}$ \\
& ii) Paediatric centre & 50,000 & $500 \mathrm{~m}^{2}$ to $800 \mathrm{~m}^{2}$ \\
& lii) Geriatric centre & 50,000 & $500 \mathrm{~m}^{2}$ to $800 \mathrm{~m}^{2}$ \\
\hline
\end{tabular}

Source: DDA 2007 
These norms do not include Mohalla Clinics, as the formulation of the master plan predates the idea of Mohalla Clinics. Mohalla Clinics are intended to function as the lowest tier of healthcare service in Delhi; therefore the present study proposes that the population norms of the 'dispensary' can be applied for Mohalla Clinics.

At the primary level healthcare is provided by GoNCT-D and the local bodies, as shown in Table 2 (see also Figure 7).

Table 2: Public (primary) health facilities in Delhi, by size of population served and provider, as at 20.04.19

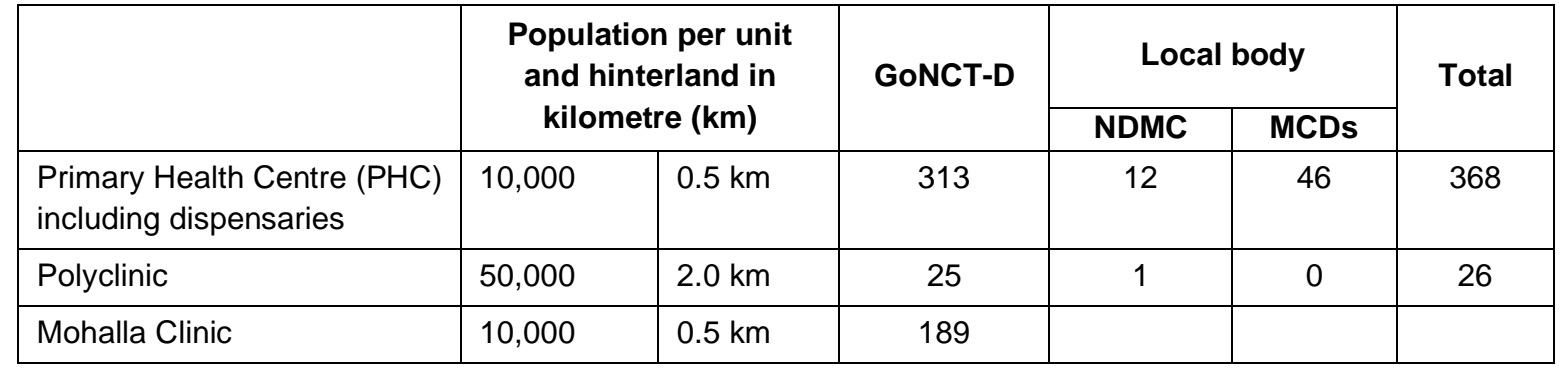

Sources: GoNCT-D, NDMC, MCD; compiled by the authors

Figure 7: Primary healthcare facilities in Delhi

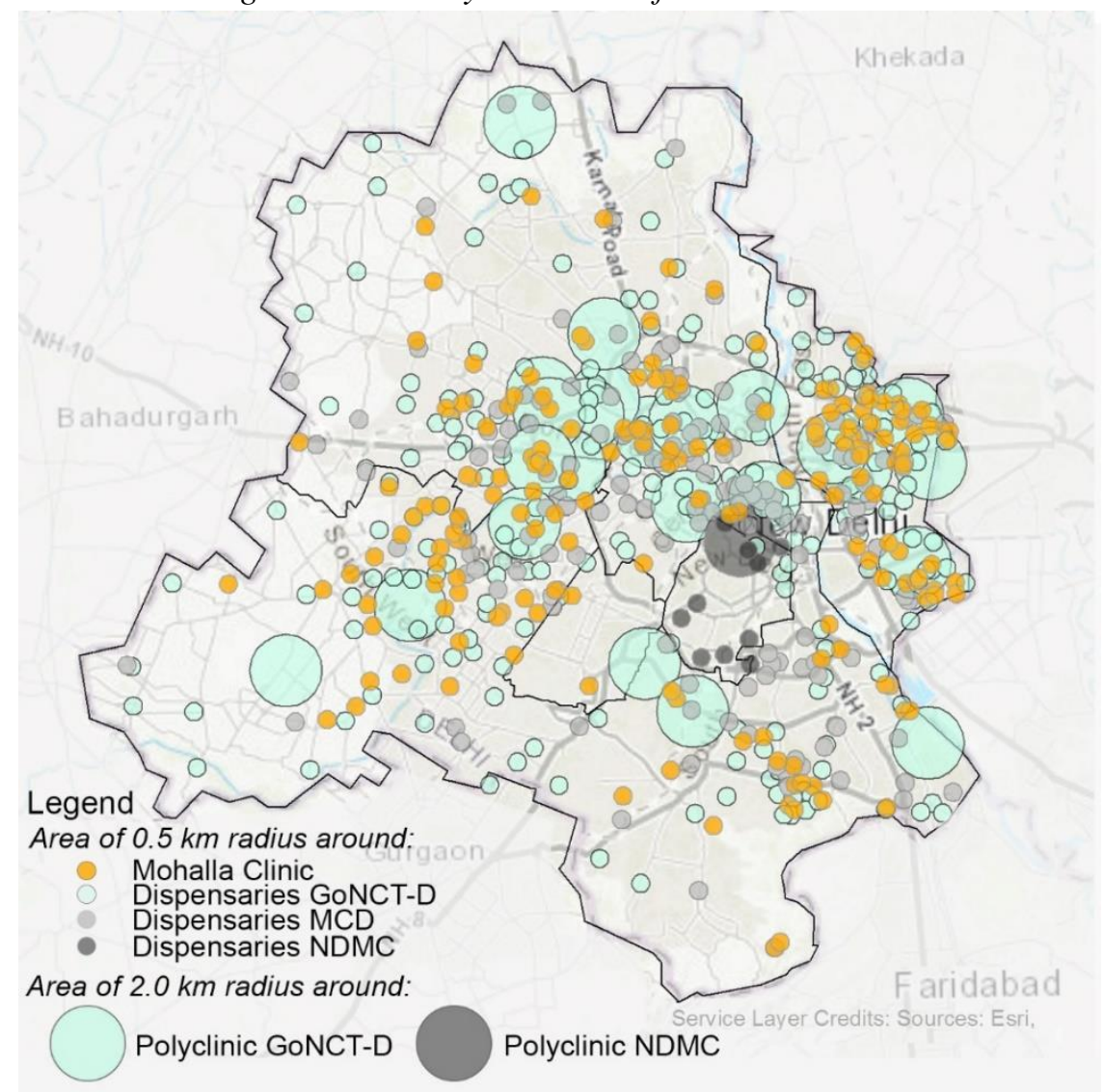

Sources: Ministry of Health, GoNCT-D, ${ }^{5}$ compiled by the authors

\footnotetext{
${ }^{5}$ The authors geocoded the locations (address) of the Mohalla Clinics, various dispensaries and polyclinics which were sourced from the Ministry of Health, GoNCT-D in March 2019.
} 


\section{Mohalla Clinics}

This study focuses mainly on Mohalla Clinics. The concept of the Mohalla Clinic is to provide quality primary healthcare services on the doorstep of local communities in Delhi. These clinics were commissioned as a direct result of AAP's promise to improve primary healthcare in its party manifesto.

There is widespread acknowledgement that Mohalla Clinics have improved access to health services by qualified providers, for the poorest of the poor, in Delhi. They have also brought health, education and social services back to the forefront of politics and governance (Lahariya 2017). These clinics featured prominently in the AAP's campaign for GoNCT-D elections in February 2020, along with the other works carried out by AAP while in power at NCT. In the event, the AAP won the elections again with a comfortable majority (Bhaduri 2020).

According to the GoNCT-D website (2017a), Mohalla Clinics are to provide the following services:

1. Primary medical care based on standard treatment protocols, including curative care for common illnesses (fever, diarrhoea, skin disease, respiratory trouble etc.), first aid and referral services.

2. A referral service for lab investigations, which are to be carried out by an accredited partner laboratory.

3. Medicines, free of cost to patients, based on the essential drug list published by the Delhi government.

4. Preventive services such as antenatal and postnatal care of pregnant women and new mothers, assessment of nutritional status and counselling; and the preventive and promotive components of ongoing national/state health programmes.

5. Health information, education and awareness.

\section{Objectives}

The present research aims to understand the promises and practices of Mohalla Clinics, with particular emphasis on their governance and the politics surrounding it. The specific research objectives are:

1. Evaluation of community participation in Mohalla Clinics and their effects on the performance of the clinic.

2. Comparing the promises for participation in running Mohalla Clinics with actual practices.

3. Propose measures to improve efficiency and sustainability of Mohalla Clinics. 
Through this research, we attempt to assess whether the Mohalla Clinics have delivered on the government's promise of making primary healthcare more accessible to the people and the role of community participation in the process.

\section{Methods}

The study is based on a case-oriented mixed-methods fieldwork in five different areas of Delhi (Figure 8) which have a Mohalla Clinic. Mixed methods were used to ensure we captured perceptions about the Mohalla Clinics' functioning and governance. This was done through qualitative semi-structured interviews of various government officials involved with the Mohalla Clinics and other stakeholders like Members of Legislative Assembly (MLAs), municipal ward councillors, local leaders, landlords, doctors in the clinics and people living in the case study area or the neighbourhood of the clinic. These were then triangulated with the qualitative data received from the patient's survey to understand the functioning of these Mohalla Clinics. The fieldwork was conducted in February and March 2019.

Figure 8: Case studies

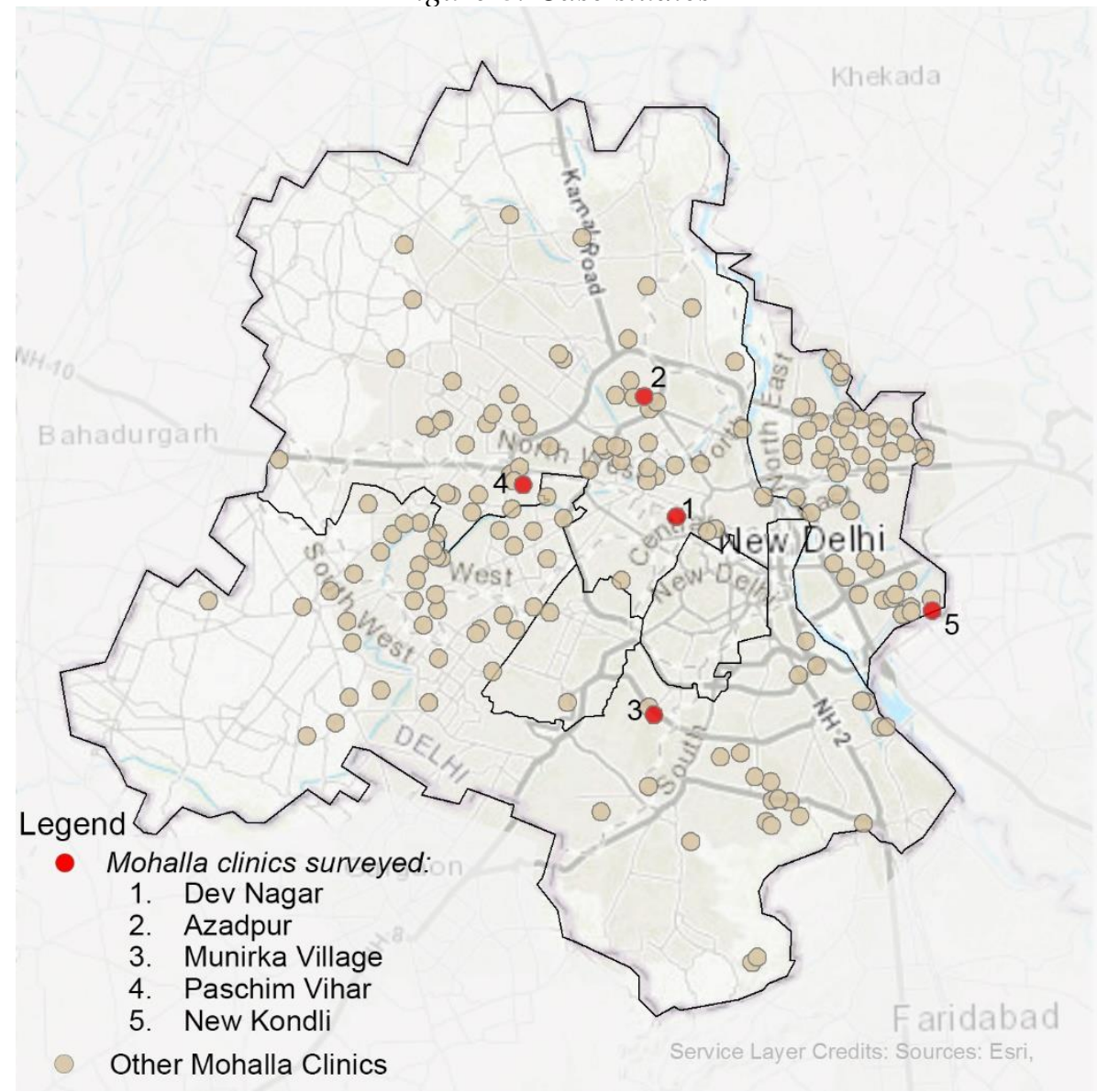

Source: Authors 
Dev Nagar, with the highest Scheduled Caste (SC) ${ }^{6}$ population (69\%) in Delhi, is an example of a lowincome neighbourhood. Here, the SC population is taken as a proxy for income data. Similarly, Azadpur is also an example of a low-income neighbourhood, and the Mohalla Clinic is located in Azadpur fruit mandi (i.e. wholesale market) where casual workers make their living. Munirka Village and Paschim Vihar are examples of affluent neighbourhoods. New Kondli is just $1.5 \mathrm{~km}$ away from the NCT boundary. These areas were selected to understand how the Mohalla Clinics operate in neighbourhoods with different income groups, and to establish whether people from outside NCT also use the clinics.

In the areas mentioned above, primary surveys were conducted among 30 randomly selected users of the clinics to understand the accessibility, waiting time, cost incurred and to compare these parameters of Mohalla Clinics to the healthcare facilities they were using. Semi-structured interviews were also conducted in this area with both users and non-users randomly selected in an area within 500 metres (m) of each clinic. The non-users were asked their reasons for not using the Mohalla Clinic. The users were asked about advantages and disadvantages of the clinic, willingness to participate in improving the operations of the clinic, opinion on community participation for health services, willingness to pay for primary health services, distance travelled to access clinic services, travel time, travel cost, and waiting time in the clinic. Additionally, interviews were conducted with the doctors at the Mohalla Clinics. However, in all the five clinics, the auxiliary nurse midwife and pharmacist refused to speak to the authors, directing them to the doctor whenever they were approached for an interview. Two MLAs, ward councillors and leaders of the local Jhuggi Jhopri Cluster (JJC meaning 'slum cluster') were also interviewed along with officials working at the Department of Health and Family Welfare, GoNCT-D.

Semi-structured interviews of parents of students studying in GoNCT-D schools were conducted to understand the community participation there and to compare it with Mohalla Clinic's framework of participation.

We have also analysed secondary data for this study consisting of Census 2011, MPD 2021, government reports such as the National Health Policy 2017, National Urban Health Mission guidelines, various cabinet notes related to Mohalla Clinics and much other relevant data (published or unpublished) from GoNCT-D (e.g. the list of functional Mohalla Clinics, the list of rented Mohalla Clinics, and a list of sites handed over to the Public Works Department (PWD)). We referred to several newspaper reports in 2020 to understand the impact of the coronavirus disease 19 (COVID 19) pandemic.

\footnotetext{
${ }^{6}$ Scheduled Caste are a group of people recognised officially by the Indian constitution as socially and economically weak because they were historically discriminated against and require affirmative action. The study uses them as proxy for an economically weak section.
} 


\section{Limitations}

The authors would like to highlight two principal limitations of the methodology described above. First, there may be recall bias in the study, as users were asked to compare their Mohalla Clinic's services to the healthcare facilities they were using prior to Mohalla Clinics. Second, seasonality of morbidity may also be a limitation in this comparison, as the survey was conducted in February and March 2019, while the recalled data may relate to other months.

\section{Results}

This section discusses the study's findings relating to each of the research objectives. These objectives are:

1. Evaluation of community participation in Mohalla Clinics and its effects on the performance of the clinic.

2. Comparing the promises for participation in running Mohalla Clinics with actual practices.

3. Proposing measures to improve efficiency and sustainability of Mohalla Clinics.

\section{A curative initiative with people playing the role of beneficiaries?}

The evaluation of community participation in Mohalla Clinics was carried out by applying the framework provided by Rifkin (1986) in Figure 1. The top-level findings were as follows:

1. Planning (health programmes): All details about the planning of healthcare facilities in the Mohalla Clinics, such as the list of free medicines, diagnostic tests and operation timings, are decided by GoNCT-D. However, it is up to the doctors in the clinics to provide these facilities. The researchers observed that the clinics were not providing antenatal or postnatal care, assessment of nutritional status, counselling, preventive or promotive care, or health information, education and awareness. Instead, the Mohalla Clinic was understood by its staff as a purely curative initiative.

2. Monitoring and evaluation: Monitoring of some few clinics is done by the Wadhwani Initiative for Sustainable Healthcare (WISH) Foundation, a Non-Governmental Organisation (NGO) partner. The rest of the clinics are supposed to be monitored remotely by the chief district medical officer through Information and Technology (IT) based monitoring tools (GoNCT-D 2015). However, no such monitoring was observed on the ground. None of the clinics visited had, for example, closed-circuit television (CCTV) cameras or computerised data entry systems to enable transparent monitoring.

3. Activities: Communities have no role in selecting or implementing the activities of the Mohalla Clinics as PWD constructs the clinics, and the clinic's staff carries out all activities.

4. Implementation: The implementation of the scheme, including site selection, is also top-down (see Figure 9). The first 100 clinics were set up in properties rented from private owners. PWD 
would set the rent for these, however, the property owners were not satisfied with these rates. ${ }^{7}$ Opposition political parties have also alleged misconduct regarding the rents' disbursement (Bhatnagar 2016). There is also no standard size for the rental clinics. These reasons have resulted in GoNCT-D discontinuing the practice of opening Mohalla Clinics in privately rented premises. Since 2017, GoNCT-D mainly constructs the clinics in temporary structures (called Portacabins; short for 'portable cabins') on sites where it owns the land. ${ }^{8}$

Figure 9: Site selection process for Mohalla Clinics

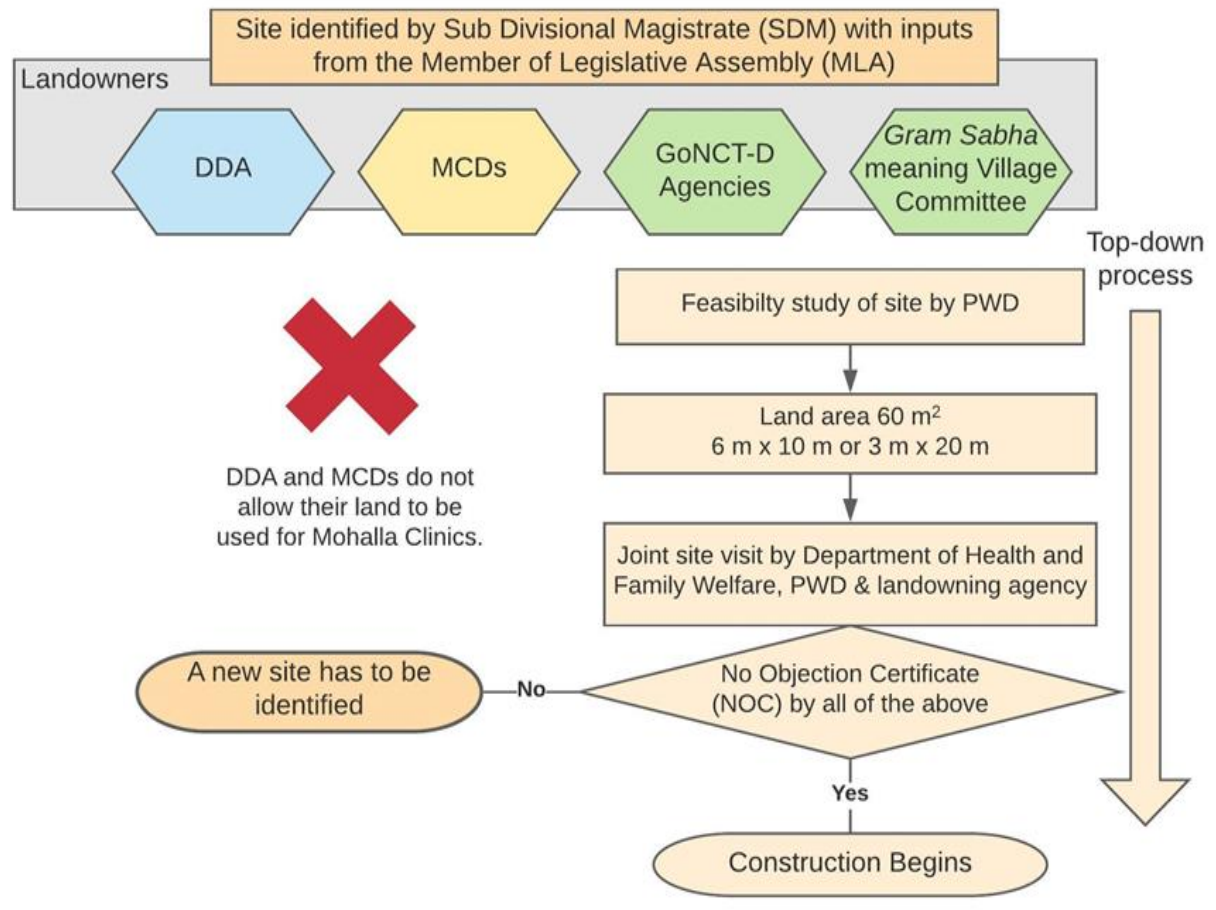

Source: Authors, based on semi-structured interviews with officials of GoNCT-D

\section{The salient issue of site selection}

According to officials in the Department of Health and Family Welfare, using land already owned by the DDA and the MCDs is not an option, as despite extensive negotiations these bodies are not willing to make it available (Figure 10). (The three MCDs are also governed by a different political party, namely the BJP, which further complicates matters.) This information was corroborated through interviews with the MLA, ward councillors and residents living near the site of an under-construction Mohalla Clinic. ${ }^{9}$ The research also found that initiating a Mohalla Clinic at a site is a prolonged process. Only 189 out of the 1,000 targeted clinics had become functional by April 2019. However, according to semi-structured interviews with GoNCT-D officials, another 290 sites had been handed over to the PWD for construction, and negotiations with Delhi Metro Railways Corporation (DMRC) were

\footnotetext{
${ }^{7}$ Interview with a landlord of Mohalla Clinic in February 2019. Also mentioned by officials in GoNCT-D as a reason to discontinue this practice.

${ }^{8}$ Interview with officer on special duty / secondment to the health minister in March 2019.

${ }^{9}$ Interviews with MLA, ward councillors and residents were conducted in March 2019.
} 
underway for another 83 Mohalla Clinic sites in metro railway stations. The agencies rent out the land, although the rent is negligible

Figure 10: Landowning agencies of 290 sites handed to PWD

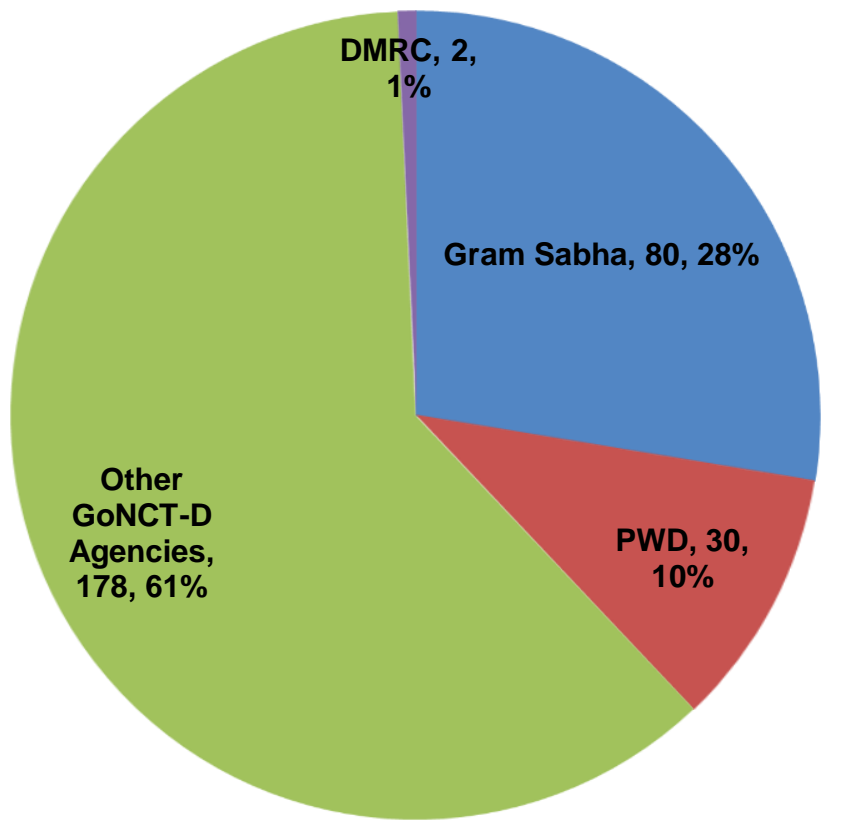

Source: GoNCT-D data, compiled by the authors

As of April 2019, sites for only 562 clinics of the 1,000 initially promised had been identified - four years after initiation of the programme in 2015 (Figure 11). This delay suggests that the top-down decision-making approach adopted for what should be local decentralised amenities is time-consuming and arguably counterproductive. Although unforeseen delays can occur at all levels of decision-making, the process of site selection involves different levels of governments and their agencies which do not want to cooperate. The MCDs, which are the lowest level of government, control most of the land and are involved in the site selection process.

This top-down process has also led to an oversupply of Mohalla Clinics in some areas and undersupply in other areas, as indicated in Figure $12 .{ }^{10}$ It is clear (from Figure 12) that Mohalla Clinic sites are not selected on the basis of need by the ward, neighbourhood or community, but rather on the basis of availability of land.

\footnotetext{
${ }^{10}$ Based on the planned ratio of one clinic for 10,000 people and comparing to the population of the wards.
} 
Figure 11: Mohalla Clinics (existing and proposed)

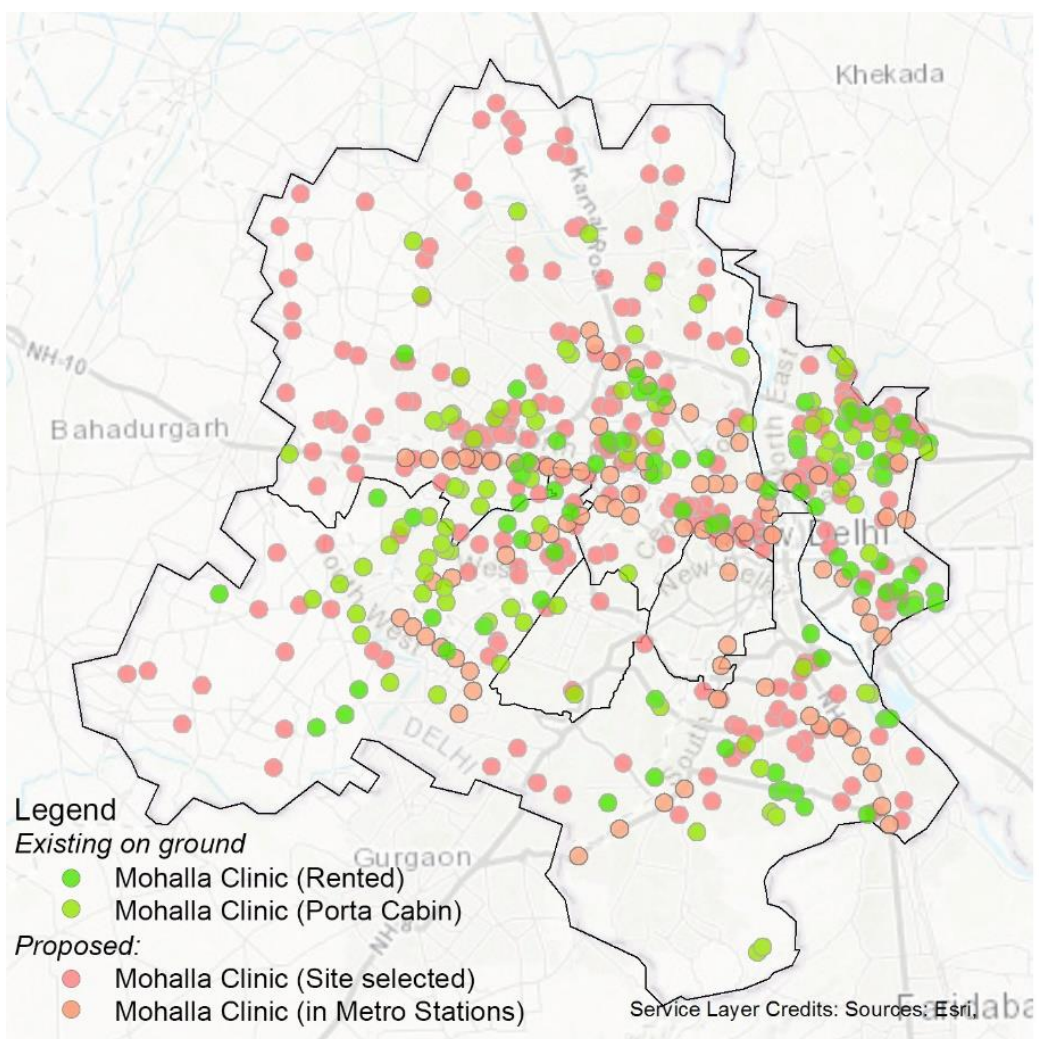

Source: GoNCT-D data, compiled by the authors

Figure 12: Distribution density of PHCs and Mohalla Clinics

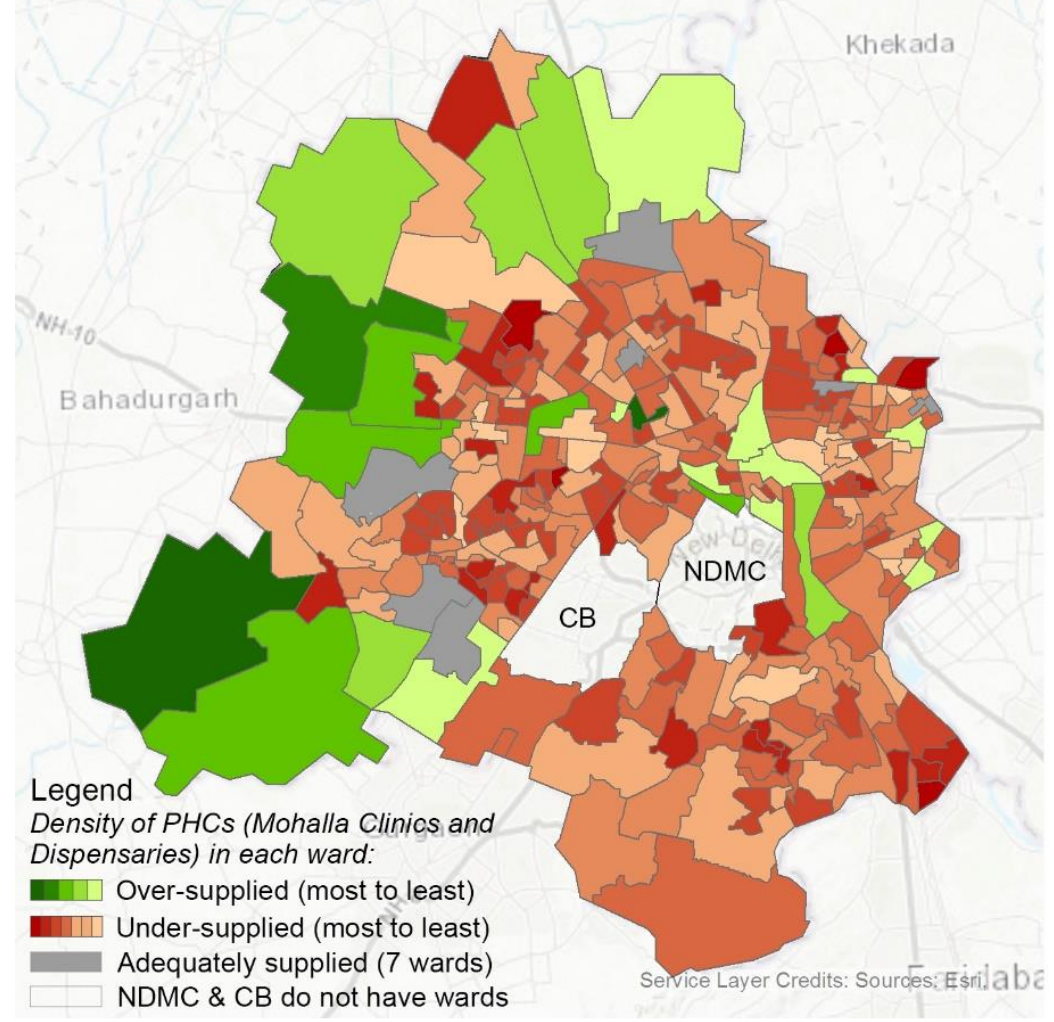

Source: Compiled by the authors 
In total there are 562 existing or proposed (with a site identified) Mohalla Clinics. However, these fail to cover 282 JJCs out of the 675 JJCs in Delhi - i.e. $42 \%$ of JJCs have no Mohalla Clinic within $500 \mathrm{~m}$ (Figure 13). Of these $282 \mathrm{JJCs}, 60 \%$ - i.e. $172 \mathrm{JJCs}$ - have no public health services of any kind within $500 \mathrm{~m}$ and are hence extremely vulnerable (Figure 14). It would appear therefore that GoNCT-D is constructing the Mohalla Clinics indiscriminately, i.e. without prioritising need, in order to meet its target of 1,000 clinics. This mis-prioritisation is likely to have an effect on the sustainability of the programme.

Figure 13: JJCs without a Mohalla Clinic within $500 \mathrm{~m}$

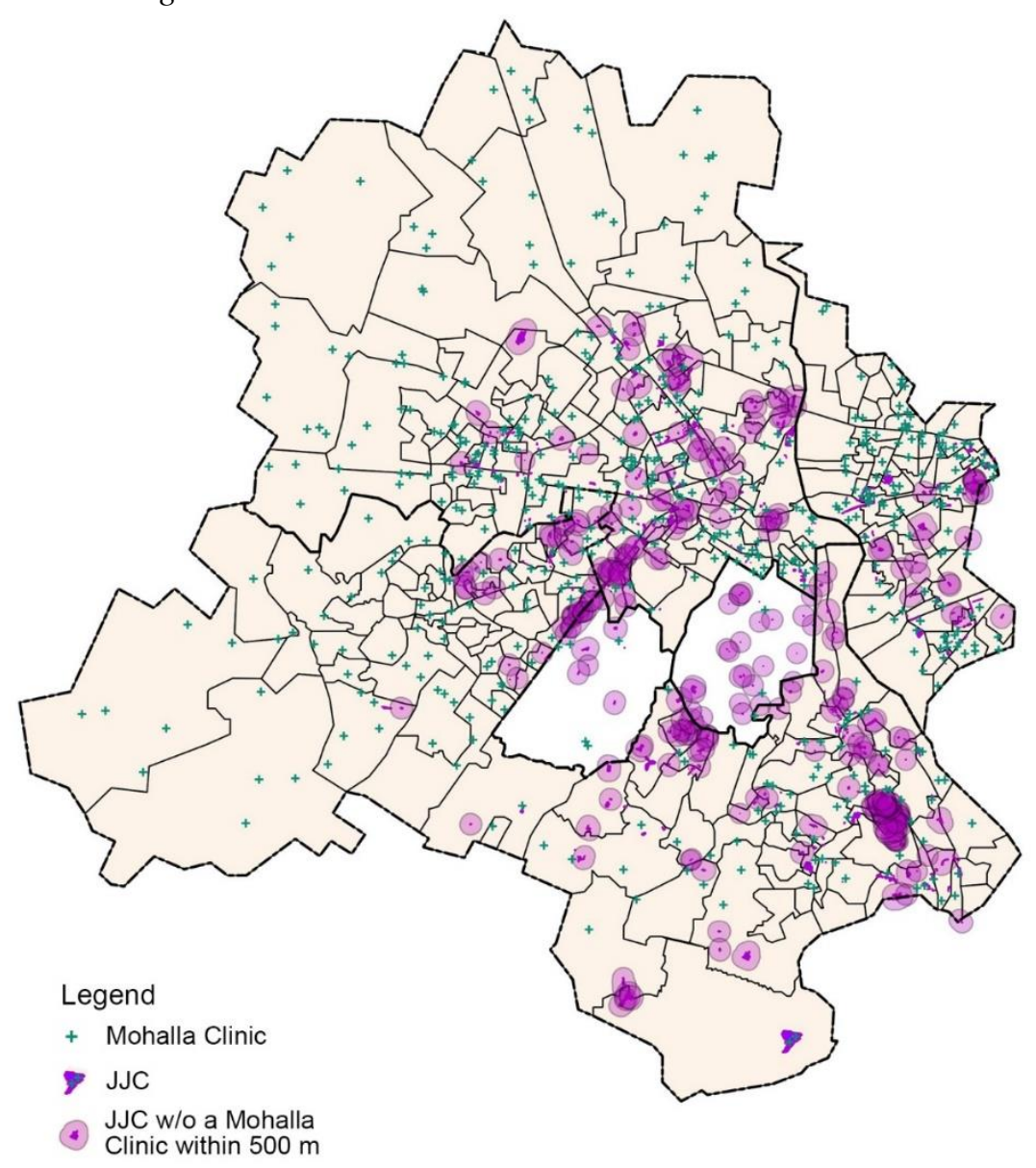

Source: GoNCT-D data, compiled by the authors 
Figure 14: Slums (JJC) without any public health services within $500 \mathrm{~m}$

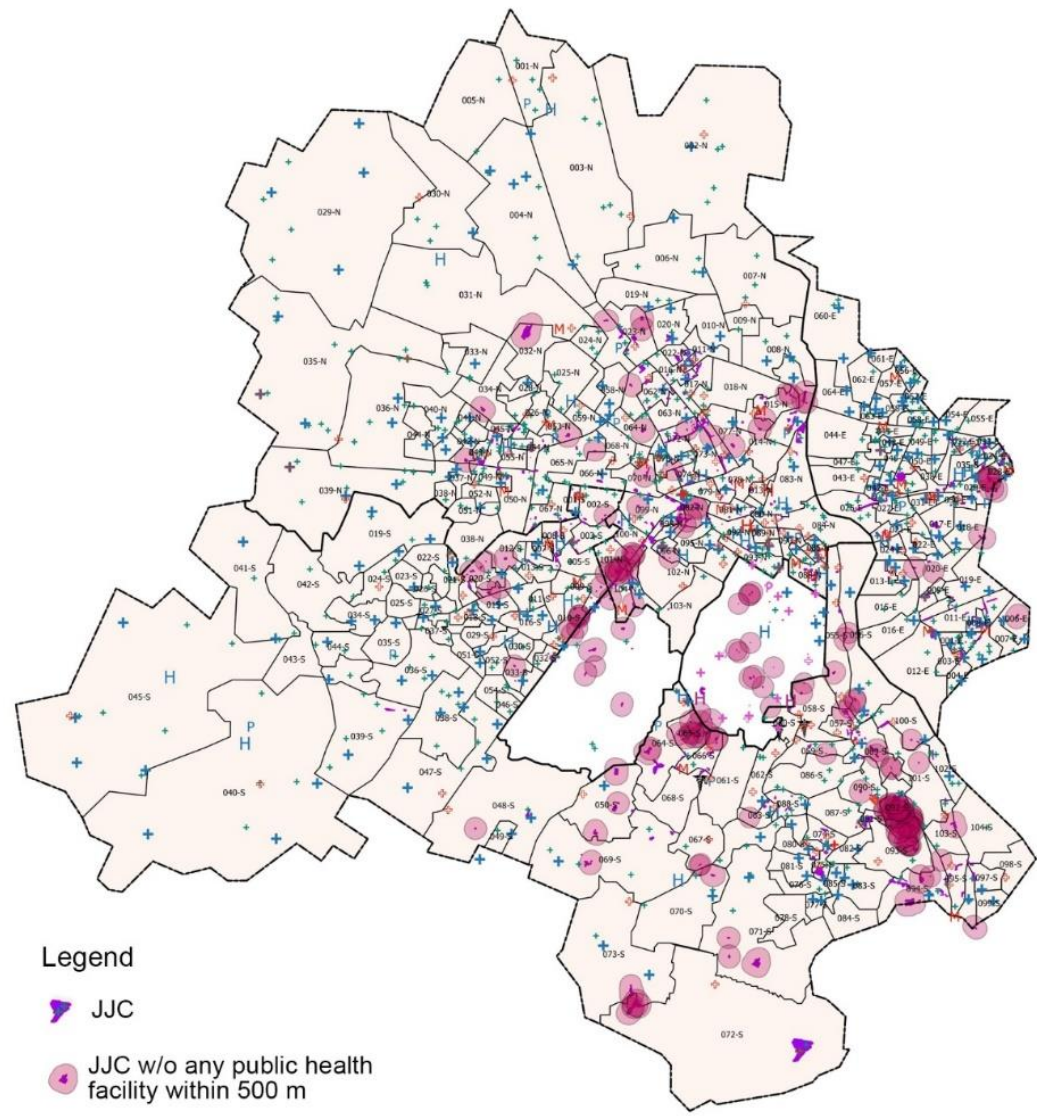

Source: GoNCT-D data, compiled by the authors

So far, the study has established that the role of the community in Mohalla Clinics is that of beneficiaries only, and not as decision-makers for activities or implementation of the clinics. The researchers were keen to find out why this was and have elaborated on it further in the subsequent sections.

\section{Performance of Mohalla Clinic as provider of primary urban health services}

This section analyses the performance of Mohalla Clinics as a provider of health services based on the interviews and surveys conducted in the study areas. Residents living within $500 \mathrm{~m}$ of a clinic who did not use the clinic cited a range of reasons. These included having no need to go to the doctor for primary healthcare services; needing healthcare of secondary level and above; having an alternative such as Central Government Health Scheme (CGHS) dispensaries available to them; being able to afford private healthcare; finding that a particular medical test is unavailable; finding that the opening hours of Mohalla Clinics do not suit them, or simply being unaware of the Mohalla Clinics. ${ }^{11}$

However, for those residents who do use them, the clinics have provided several substantial benefits, discussed below.

${ }^{11}$ Semi-structured interviews with residents living within $500 \mathrm{~m}$ of a Mohalla Clinic, conducted in March 2019. 


\section{Accessibility}

First, they are accessible to the people. The average distance travelled by the users is $1.3 \mathrm{~km}$ and about $51 \%$ of users live within $500 \mathrm{~m}$ of a clinic (Figure 15). Average travel time is 18 minutes and the average travel cost negligible. This goes to show that Mohalla Clinics bridge some of the gaps in access to healthcare in the existing system.

\section{Figure 15: Localities from which users come to Mohalla Clinics}

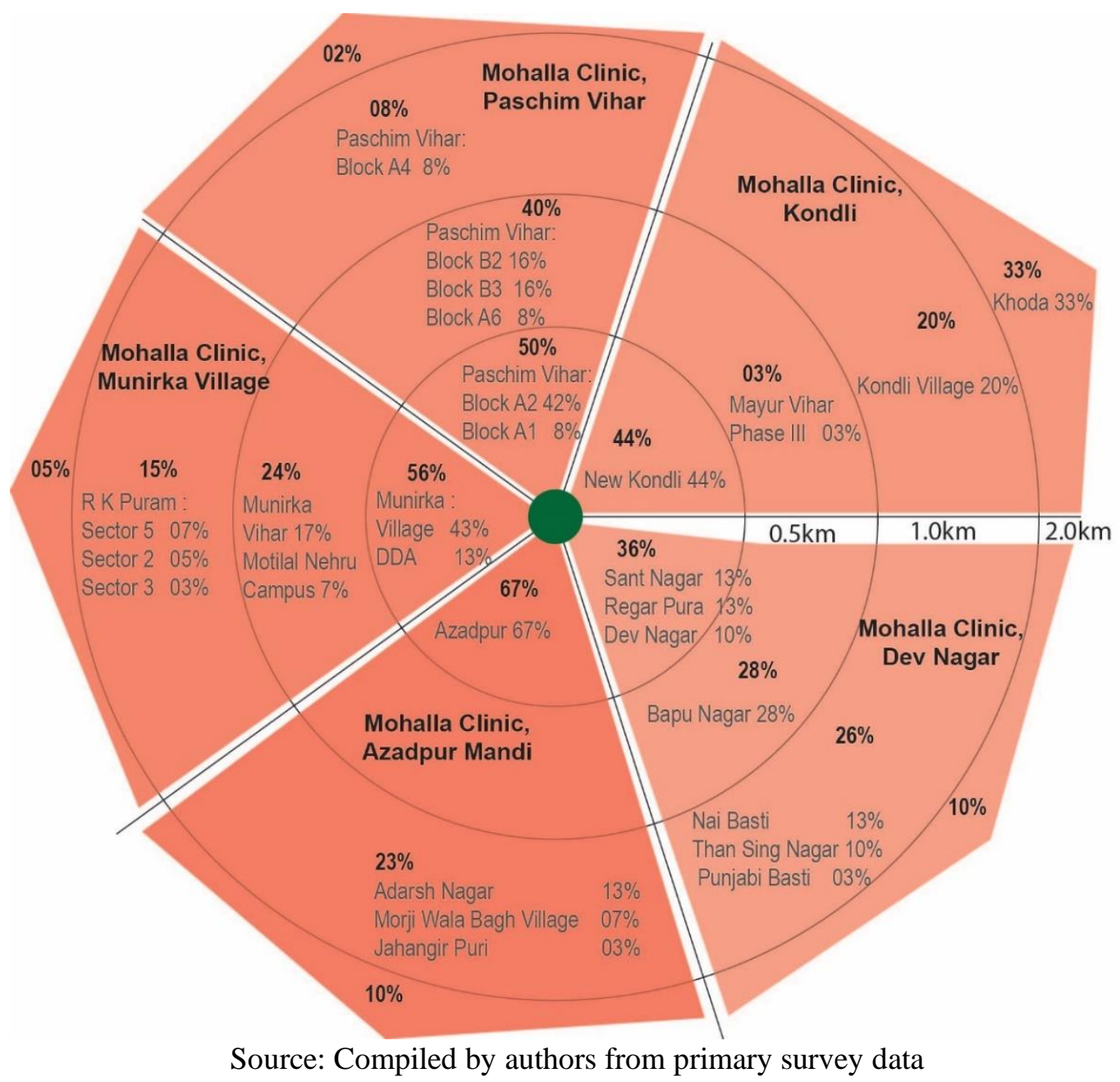

Before the Mohalla Clinics, these patients either used alternative government or private healthcare facilities or self-diagnosed and -medicated (Table 3). 
Table 3: Healthcare facilities used before opening of Mohalla Clinics

\begin{tabular}{|c|c|c|c|c|c|c|c|c|c|c|c|c|}
\hline \multirow[b]{2}{*}{$\begin{array}{l}\text { Mohalla } \\
\text { Clinic } \\
\text { Location }\end{array}$} & & \multirow[b]{2}{*}{$\begin{array}{l}\text { Monthly } \\
\text { HH } \\
\text { Income } \\
\text { (INR) }\end{array}$} & \multicolumn{6}{|c|}{ Government Facility } & \multicolumn{3}{|c|}{ Private } & \multirow{2}{*}{$\begin{array}{c}\% \text { Self- } \\
\text { diagnosing/- } \\
\text { medicating } \\
\end{array}$} \\
\hline & & & $\begin{array}{l}\% \\
\text { Users }\end{array}$ & $\begin{array}{c}\text { Distance } \\
\text { Travelled } \\
(\mathrm{km})\end{array}$ & $\begin{array}{l}\text { Travel } \\
\text { Time } \\
\text { (hours) }\end{array}$ & $\begin{array}{l}\text { Travel } \\
\text { Cost } \\
\text { (INR) }\end{array}$ & $\begin{array}{l}\text { Waiting } \\
\text { Time } \\
\text { (hours) }\end{array}$ & $\begin{array}{l}\text { Total } \\
\text { Time } \\
\text { (hours) }\end{array}$ & $\begin{array}{l}\% \\
\text { Users }\end{array}$ & $\begin{array}{l}\text { HH Expenditure } \\
\text { on Health (INR) }\end{array}$ & $\begin{array}{l}\text { HH Expense } \\
\% \text { of } \mathrm{HH} \\
\text { Income }\end{array}$ & \\
\hline \multirow{3}{*}{$\begin{array}{c}\text { Opp. } \\
\text { Khalsa } \\
\text { College, } \\
\text { Dev } \\
\text { Nagar }\end{array}$} & Maximum & 15,000 & \multirow{3}{*}{$73 \%$} & 7.8 & $1: 00$ & 40 & 5:00 & $6: 00$ & \multirow{3}{*}{$14 \%$} & 2,090 & $14 \%$ & \multirow{3}{*}{$13 \%$} \\
\hline & Average & 8,900 & & 2.0 & $0: 20$ & 24 & $2: 30$ & $2: 50$ & & 1,220 & $14 \%$ & \\
\hline & Minimum & 5,000 & & 0.5 & $0: 05$ & 10 & $0: 10$ & $0: 15$ & & 350 & $7 \%$ & \\
\hline \multirow{3}{*}{$\begin{array}{c}\text { A-2 } \\
\text { Paschim } \\
\text { Vihar }\end{array}$} & Maximum & 50,000 & \multirow{3}{*}{$42 \%$} & 1.5 & $0: 10$ & 10 & $0: 10$ & $0: 20$ & \multirow{3}{*}{$58 \%$} & 2,000 & $4 \%$ & \multirow{6}{*}{ NIL } \\
\hline & Average & 21,500 & & 0.8 & 0:06 & 3 & 0:05 & $0: 11$ & & 1,250 & $6 \%$ & \\
\hline & Minimum & 6,000 & & 0.2 & $0: 05$ & 0 & 0:07 & $0: 12$ & & 600 & $10 \%$ & \\
\hline \multirow{3}{*}{$\begin{array}{l}\text { New } \\
\text { Kondli }\end{array}$} & Maximum & 30,000 & \multirow{3}{*}{$60 \%$} & 8.0 & $2: 00$ & 50 & 7:00 & 9:00 & \multirow{3}{*}{$40 \%$} & 2,500 & $8 \%$ & \\
\hline & Average & 11,733 & & 4.0 & $0: 40$ & 30 & 3:35 & $4: 15$ & & 805 & $7 \%$ & \\
\hline & Minimum & 4,000 & & 0.3 & $0: 10$ & 10 & $0: 10$ & $0: 20$ & & 100 & $3 \%$ & \\
\hline \multirow{3}{*}{$\begin{array}{l}\text { Munirka } \\
\text { Village }\end{array}$} & Maximum & 50,000 & \multirow{3}{*}{$60 \%$} & 8.0 & $1: 30$ & 20 & 8:00 & 9:30 & \multirow{3}{*}{$27 \%$} & 2,000 & $4 \%$ & \multirow{3}{*}{$13 \%$} \\
\hline & Average & 15,200 & & 3.0 & $0: 30$ & 9 & $2: 30$ & 3:00 & & 850 & $6 \%$ & \\
\hline & Minimum & 7,000 & & 0.5 & $0: 05$ & 0 & 0:05 & $0: 10$ & & 250 & $4 \%$ & \\
\hline \multirow{3}{*}{$\begin{array}{l}\text { Azadpur } \\
\text { Mandi }\end{array}$} & Maximum & 12,000 & \multirow{3}{*}{$37 \%$} & 10 & $0: 30$ & 150 & $1: 30$ & $2: 00$ & \multirow{3}{*}{$47 \%$} & 1,070 & $9 \%$ & \multirow{3}{*}{$20 \%$} \\
\hline & Average & 9,400 & & 5.1 & $0: 16$ & 62 & $1: 10$ & $1: 26$ & & 278 & $3 \%$ & \\
\hline & Minimum & 5,000 & & 3.0 & $0: 08$ & 10 & $1: 00$ & $1: 08$ & & 70 & $1 \%$ & \\
\hline
\end{tabular}

Source: Primary survey by authors 


\section{Reduced waiting times}

There is a considerable pre-consultation delay at Mohalla Clinics: 30 minutes on average but ranging from five minutes to two hours. However, let us compare this with average waiting times in other places providing public health services in the city, such as outpatient departments of hospitals and dispensaries (which 56\% of the respondents used before their local Mohalla Clinic opened); we find that people are saving two hours and 19 minutes on average. Nor did users complain about waiting time during the survey; most users responded that they were saving time. There is, however, an inverse correlation between waiting time and income, as shown in Figure 16. It could be that in the more impoverished neighbourhoods, people have specific health needs due to poverty or a lack of healthcare earlier in life. It could also be because they have few options other than the Mohalla Clinic for primary healthcare, and the long waiting time indicates their dependency on the clinic. It may also be because people who can afford private healthcare or have other alternatives (such as a CGHS dispensary) do not use Mohalla Clinics (although the study did find a preference for GoNCT-D-run Mohalla Clinics and dispensaries over the PHCs run by the MCDs). ${ }^{12}$ However, the hypothesis that alternative healthcare providers are preferred is supported by the views of residents of the more affluent neighbourhoods, who reported that they prefer their own (private sector) doctor who knows their medical history, whose availability in the evening suits them and with whom they can make an appointment.

Figure 16: Monthly household income and waiting time

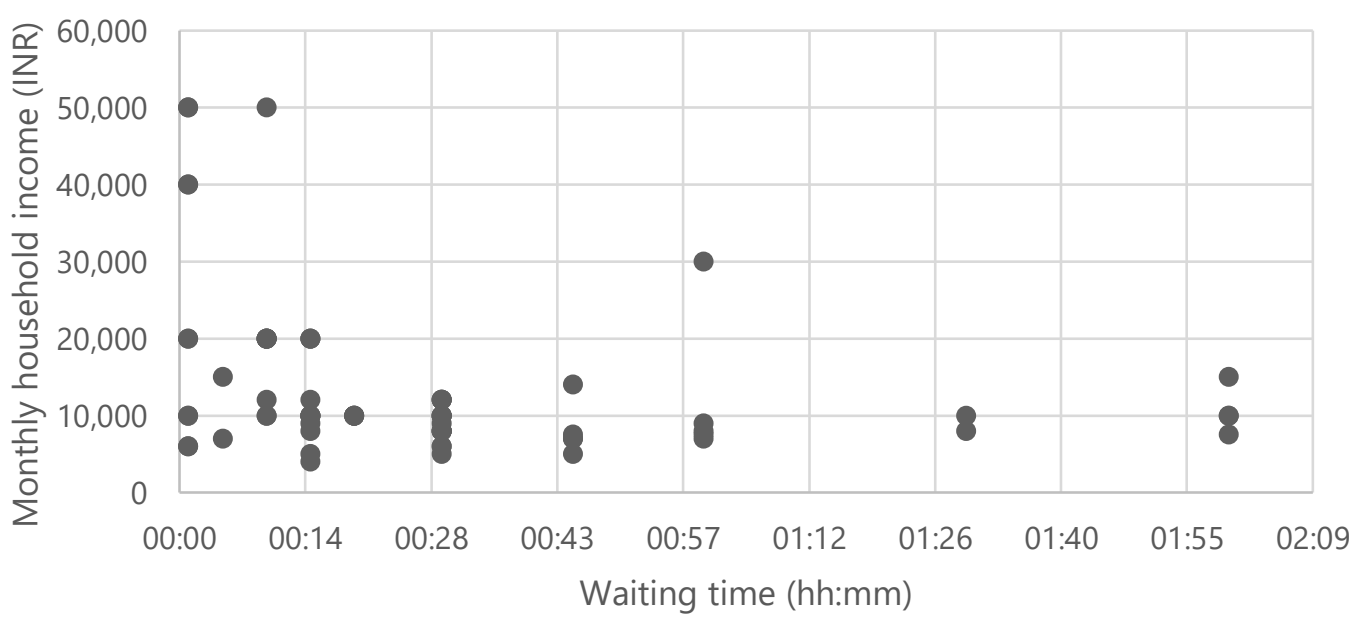

Source: Primary survey by authors

\section{Lower cost}

There is no direct cost for accessing the health services of Mohalla Clinics. The consultation, medicines and diagnostic tests are all free. Respondents who previously used private healthcare (34\%) save about $11 \%$ of their average income, i.e. INR 1,250 (USD 17) ${ }^{13}$ a month on an average. These lower costs have

\footnotetext{
${ }^{12}$ Semi-structured interviews of residents living within $500 \mathrm{~m}$ of a Mohalla Clinic, conducted in March 2019.

${ }^{13}$ As per currency exchange rate from xe currency dated $19^{\text {th }}$ December 2020

https://www.xe.com/currencyconverter/convert/?Amount=1000000andFrom=INRandTo=USD
} 
encouraged the $10 \%$ of respondents who previously practised self-medication to get proper healthcare in the Mohalla Clinics. There is, however, the opportunity cost of missing work due to the opening hours. In our survey, $57 \%$ of respondents said they had missed work due to attending the clinic, and only $18 \%$ said they had not. The remaining $25 \%$ did not work.

A number of respondents expressed dissatisfaction with regard to the clinics' opening hours, management of the diagnostic centre, and time and effort spent by the doctor on each patient. They reported that there is no way to report their dissatisfaction to GoNCT-D. Therefore, we can say that while Mohalla Clinics are improving the lives of the people, some form of community participation will improve its functioning. The next section discusses the promised participatory governance for Mohalla Clinics vis-à-vis the practice.

\section{Tangled governance and a lack of accountability}

In order to compare the promises and practices for participatory governance concerning Mohalla Clinics, it is useful to look at the history of participatory governance in Delhi. This is summarised in Figure 17. In Delhi, through the Municipal Corporation (Amendment) Act 1993 provision was made to establish ward committees at the zonal level. This was a direct consequence of the $74^{\text {th }}$ CAA. These committees consist of all the elected ward councillors within their respective zones, the nominated members of the council living in the zone, and the zonal municipal corporation officials. However, ward committees are not spaces for direct participation. Nevertheless, in India community participation in urban governance was directed in the $74^{\text {th }}$ CAA, which made it mandatory for ULBs with a population over 300,000 to form one or more tiers of governance, as a participatory space where elected councillors, administrative officers and citizen groups would work together (Patel et al. 2016b). However, not all cities created the participatory spaces as mandated and, where they were created, there were vast differences across cities in terms of composition, proximity to citizens, functions, powers and resources (Patel et al. 2016b).

Two initiatives - bhagidari (meaning 'partnership') launched in 2003 by the INC (Indian National Congress), and resident ward committees (RWCs) launched in 2008 by the BJP - were attempts by GoNCT-D and the MCD (before it was split into three) respectively at direct participation. These, however, resulted in elites capturing the invited space for participation, as only landowners were allowed to participate and, in the case of bhagidari, the local government was subverted ${ }^{14}$ (Kundu 2011; Mohanty 2014; Rao 2016).

\footnotetext{
${ }^{14}$ Bagidari had no constructional basis. The local government, i.e. the MCD comprising of elected ward councillors, were side-lined as Bagidari connected the GoNCT-D's agencies like PWD directly with the RWAs which comprised of rich landowning population, a space closed for the tenants. Also, projects carried under Bhagidar like solid waste segregation, were the responsibility of MCD.
} 
Figure 17: Incremental but fragmented initiatives of participatory governance in Delhi

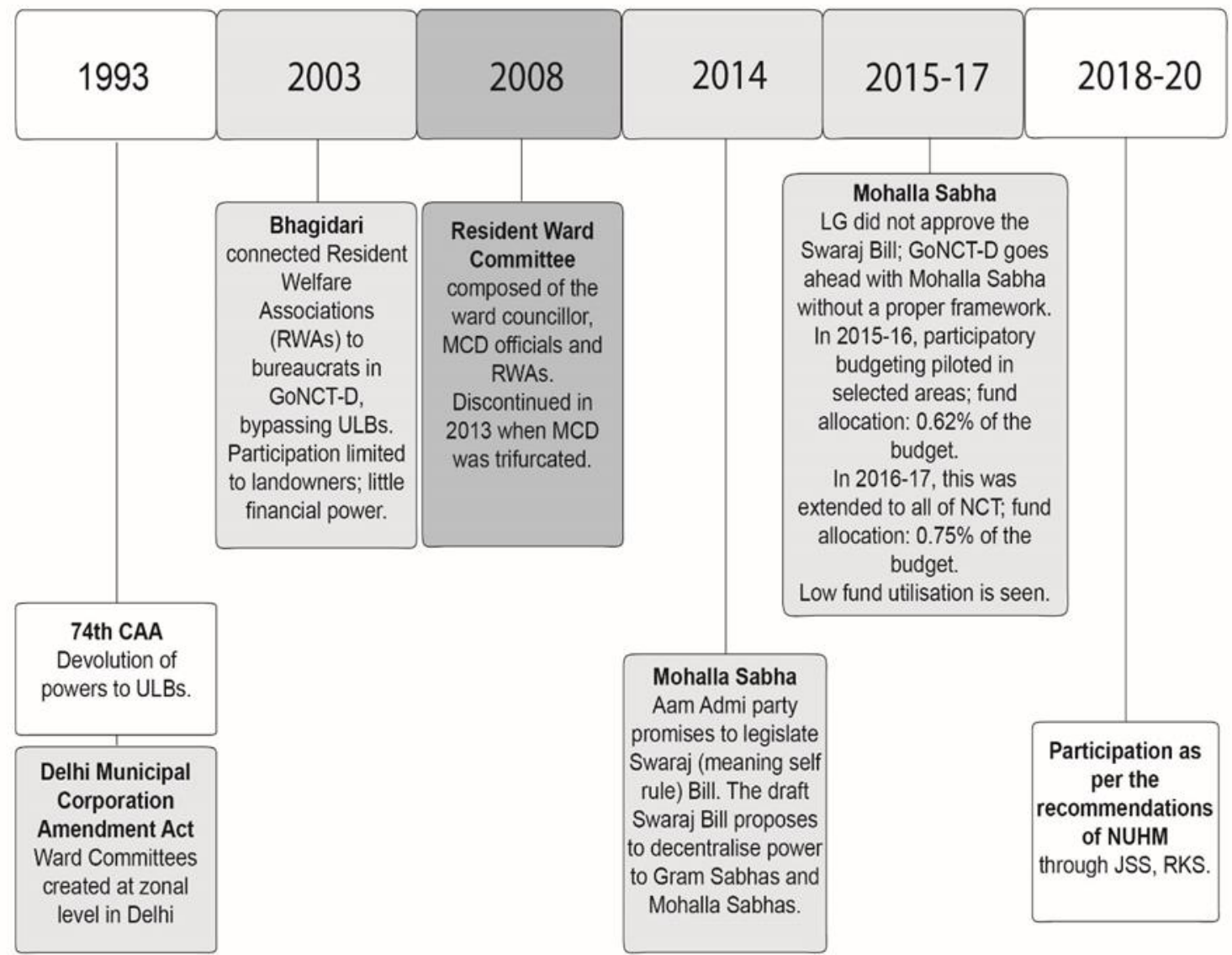

Source: Compiled by authors

The Mohalla Sabha is the latest attempt of GoNCT at participatory governance. The AAP, the ruling party in GoNCT-D, promised in its manifesto (2015) that it would be a local, visible and invited space. According to the manifesto, each ward in Delhi would be divided into 10-15 mohallas to be governed by an assembly of voters called the Mohalla Sabha. This sabha would be empowered to make decisions concerning the locality and would monitor the functioning of public institutions like the schools and PHCs, which include Mohalla Clinics (AAP 2015). However, in practice, the system of sabhas has been implemented under the GoNCT-D instead of by local bodies; the district magistrate is responsible for organising these meetings and for providing two mohalla coordinators to conduct them. Furthermore, each Mohalla Sabha's powers have been limited to urgent repairs in its neighbourhood within a budget of INR 1 Million (USD 13,595), ${ }^{15}$ according to the Mohalla Sabha website (GoNCT-D n.d.). Delhi's 'tangled governance system' is to blame for its non-performance (Rao 2016, p. 11) and ultimately, the subversion of its local governments.

GoNCT-D is also looking at participatory governance for Mohalla Clinics through the system of Jan Swasthya Samiti (JSS, or 'public health committee'). The JSS is an executive sub-committee under the

\footnotetext{
${ }^{15}$ As per currency exchange rate from xe currency dated $19^{\text {th }}$ December 2020 https://www.xe.com/currencyconverter/convert/?Amount=1000000andFrom=INRandTo=USD
} 
Rogi Kalyan Samiti (RKS, or 'patient welfare committee') system which the NUHM 2013 recommends every PHC (and Mohalla Clinic) to set up (GoNCT-D 2018). The JSS comprises of a nominated president with a background in medicine, corporate management, education or social work; a secretary who is the Medical Officer (MO) in charge; a treasurer who is the pharmacist; two other officer members; and two members (one of which must be a woman) who are nominated by the chief district medical officer. The committee's function is to prepare action plans for the health centres, keep track of funds, monitor compliance in standards, review the services provided, and attend to public grievances (GoNCT-D 2018).

There are, however, some significant concerns with the JSS system. According to one respondent, JSS members are neither interested in the meetings nor accountable to anyone - indeed, they sometimes delegate their meetings to others. Also, because the process of setting up JSSs is in its initial stages, on the ground, neither Mohalla Clinic doctors nor the patients surveyed are aware of the JSSs. The JSS, therefore, is a local, closed and hidden space.

When respondents were asked their view of community participation in Mohalla Clinics, they gave divided responses. Some people thought the community should decide the operating hours, and oversee the management of diagnostic sample collection in the clinics; that is, they wanted the community to be involved in some activities and some aspects of implementation at their Mohalla Clinic. Others thought that the community should take part in the monitoring and evaluation of services in clinics. On the other hand, some respondents thought the community did not have the capacity for these tasks, which were, therefore best, left to professionals (i.e. doctors). As for respondents who were doctors and officials, they seemed reluctant to see community members in any position with decision-making power, claiming that this would lead to delays.

\section{Mohalla Clinics during COVID-19}

On a positive note, Mohalla Clinics have improved access to healthcare for ordinary people during the COVID-19 pandemic of 2020, as the major hospitals of the city have been treating patients with COVID-19 and the private clinics have been shut (Dutt and Chitlangia 2020). During the lockdown, ${ }^{16}$ however, reports of some Mohalla Clinics being shut, despite the instructions of the chief minister, came to light. It turned out this was due to the inability of those staff who were contract workers to commute to their place of work, as they had no identity proof or travel facility (Babu 2020). Further, there were reports of some doctors and staff in Mohalla Clinics testing positive for Covid-19 (The Statesman 2020; Times Now News 2020); however, this was the case with all healthcare professionals in Delhi (Ghosh 2020).

\footnotetext{
${ }^{16}$ Lockdown responding to the COVID 19 pandemic was announced in India on $25^{\text {th }}$ May until $31^{\text {st }}$ May2020. There has been phased reopening of activities in all areas (except containment zones) with some restrictions since $01^{\text {st }}$ June 2020.
} 
Interestingly, the doctors of the Mohalla Clinics in and around Azadpur Mandi were given an additional responsibility during the pandemic: to test people working in the wholesale market for Covid-19 (Asian News International 2020). This indicates that the staff of Mohalla Clinics can be a valuable asset to the city in times of epidemic or any other medical emergency. Since the end of lockdown, Mohalla Clinics are also being used as COVID-19 test centres (Bedi and Sirur 2020), and GoNCT-D also plans to deliver vaccines through Mohalla Clinics (Press Trust of India 2020).

The following section discusses recommendations to improve the efficiency and sustainability of Mohalla Clinics.

\section{Policy recommendations}

GoNCT-D currently shares responsibility for healthcare with local governments. It is the local bodies who are responsible for the preventive aspects of healthcare such as antenatal and postnatal care, immunisation drives, health education, solid waste management etc. Mohalla Clinics however are run by the GoNCT-D - not local bodies. We have recommended that because GoNCT-D has better resources the power and responsibility for healthcare should be with them and sanitation can continue to be with the local governments. MCD dispensaries and PHCs can also be converted to Mohalla Clinics and provide a better quality of service. This will also avoid redundancies in the health infrastructure of the city and the two governments will not be competing with each other while providing a public service.

There is no community participation in planning the healthcare programmes, or in their implementation: these are top-down activities in Mohalla Clinics. The government did initially attempt to get the community involved in monitoring clinics and participating in their activities through setting up a management committee, which was planned to have four to five volunteers (GoNCT-D 2017b) - but it is not functional on the ground. Instead, these functions also are top-down. In their current form, therefore, Mohalla Clinics are limited to providing primary curative healthcare, and in this form, they have achieved some success.

The top-down process for planning and management, however, is not proving successful, and the authors believe this will adversely impact the Mohalla Clinics in the long term. It is very tempting at this point to claim that community participation can solve all these problems; however, studies have shown that this line of thought by planners in the past has led to the failure of participation programmes (Rifkin 1996). Therefore, it is essential to consider which processes are best managed through participation and which through top-down decision-making.

Mohalla Clinics have shifted the approach to primary healthcare away from vertical health programmes (such as the nationwide Pulse Polio vaccination programme) and towards horizontal interventions, where a single clinic is looking at all diseases, communicable or non-communicable and even other 
problems in general physical health, in a neighbourhood. However, Mohalla Clinics alone cannot provide comprehensive primary healthcare. That requires integration of public health and urban planning.

According to Verbeek (2014, p. 14), many aspects of primary health relating to mental well-being, injury due to violence, or chronic diseases due to environmental pollution can be controlled through integration of public health and urban planning. However, he cautions that both disciplines are "institutionally scattered across a tangle of administrations and policy levels, and the major connection between them is made through a generic regulatory framework with fixed environmental norms and a strictly organized environmental impact assessment" - and that this remains the case today even though urban planning started over 150 years ago in response to 19th-century unhealthy and overcrowded industrial cities. The statement certainly holds for India, and especially for Delhi where the DDA (one of whose roles is as the urban planning body) sets unrealistic standards for construction byelaws and makes impractical plans which it cannot achieve. For example, MPD 2021 suggests having one dispensary per 10,000 population, with a floor area of $800-1,000 \mathrm{~m}^{2}$, and two polyclinics per 100,000 population, with a floor area of 1,000-2,000 $\mathrm{m}^{2}$. This would mean, for a projected population of 23 million in 2021, about 460 polyclinics and 2,300 dispensaries - but these are not being implemented by the DDA. This brings us back to the importance of participatory governance.

To understand the process of participatory governance better, the authors also reviewed another model of participatory governance used in the education sector: Delhi's School Management Committees (SMCs). SMCs are mandated under the 'Right of Children to Free and Compulsory Education' Rules 2011. Each one comprises of the school principal as the chairperson, 12 elected parents/guardians (a vice-chairperson further elected from them), an elected representative from the local body funding the school (ward councillor in case of a school funded by one of MCDs or MLA in case of a GoNCT-D funded school), a teacher (selected by the teachers) and a social worker nominated by District Deputy Director of Education. Half (50\%) of the committee must be women and $75 \%$ of them have to be elected parents/guardians. The committee must meet at least every two months, with at least one-third of the committee present. No proxies or substitutions are allowed. SMCs prepare and recommend the school development plan; hold regular meetings with parents; and monitor the functioning of the school, its utilisation of grants, and its norms and standards. They bring any issues to the attention of the local authority, communicate with the community, and ensure all children over six are appropriately enrolled. The SMCs are doing well in Delhi: they are accountable to the parents of the children enrolled in their schools and, these parents are satisfied with the functioning of SMCs. ${ }^{17}$

\footnotetext{
${ }^{17}$ Semi-structured interviews of several parents of the students studying in schools run by GoNCT-D conducted in March 2019.
} 
Table 4: Comparing participation in primary health and education

\begin{tabular}{|l|c|c|}
\hline Functions & JSS (Mohalla Clinic) & SMC (school) \\
\hline Planning & $\times$ & $\checkmark$ \\
\hline Monitoring and evaluation & $\times$ & $\checkmark$ \\
\hline Implementation & $\times$ & $\times$ \\
\hline Activities & $\times$ & $\checkmark$ \\
\hline $\begin{array}{l}\text { Benefits (access to medical services in } \\
\text { case of Mohalla Clinics or education in } \\
\text { case of Schools) }\end{array}$ & $\checkmark$ & \\
\hline
\end{tabular}

Source: Compiled by authors

The rules regarding SMCs are established with clarity, which helps them function better. Also, an SMC consists of $75 \%$ elected members, whereas a JSS has no elected members. Further, in the case of SMCs the participants are parents with a direct link to and interest in the school; this motivation is missing in the case of Mohalla Clinics, as the users of the clinics are not tied to a particular clinic. This may explain why JSS members show a lack of interest, and also suggests that participatory governance at Mohalla Clinics cannot work unless there is true decentralisation of governance.

According to Olum (2014, p. 37) "the successful implementation [of decentralisation] has to take into account six preconditions, namely: the establishment of institutional mechanisms, the creation of spaces for citizens' participation, political will and civil will, capacity development at the local level, careful implementation, and democratic governance."

Delhi fulfils the first, second and the last conditions easily, but there is ambiguity in both the political will and civil will. For example, the GoI's reluctance to devolve power over land and local governance to GoNCT-D shows a clear lack of political will to decentralise. Similarly, GoNCT-D tries to create spaces for citizens' participation whenever there are opposition parties in power at a particular governance level: e.g. bhagidari were created by the INC to subvert the MCD (under the BJP), and Mohalla Sabhas are being used as a similar instrument by the AAP. People's mixed responses on participation also show ambiguity in the civil will. The people's preference for Mohalla Clinics run by GoNCT-D, ahead of PHCs run by the MCD, further indicates a lack of capacity for participation at the local level.

Given the current state of affairs and based on the findings of this study, the authors recommend that a useful first step towards meaningful community participation would be decentralisation of the process of selecting the location for clinics and including the three MDCs in it. Community voices should ideally also be heard in deciding where to site the clinics, but this may lead to delays as with the absence of a proper Mohalla Sabha, there is no proper community participation framework in place. The community can be involved in monitoring and evaluating the services of the clinic. They can also help decide opening hours for the clinics, which could end up being different in different neighbourhoods. 


\section{Measures to improve efficiency and sustainability of Mohalla Clinics}

Based on above observation and findings, we therefore suggest the following measures to improve the efficiency of Mohalla Clinics and make this a sustainable programme in the long run.

1. People in their interviews and during the survey indicated a preference for Mohalla Clinics over clinics run by other agencies like MCDs and a lot of them have stopped using the services of MCD dispensaries. This vote by feet indicates public confidence in Mohalla Clinics and GoNCT-D. Therefore, we recommend that responsibilities related to health be shifted away from MCD to GoNCT-D, a higher level of government with more money and resources to spend on health.

2. The monitoring and evaluation of the services should be community driven. It would be more economical than CCTV cameras or other IT-based surveillance and would also develop, in the community, a sense of ownership and responsibility for the Mohalla Clinic. Community voices should also be heard in deciding the operational hours of the clinic, which could end up being different in different neighbourhoods.

3. The process of site selection can be decentralised to involve the three MCDs as they are a principal landowning and land regulating agency in Delhi. This would ensure that the sites selected for Mohalla Clinics are located optimally, and it may also speed up the site selection process.

\section{Conclusion}

Mohalla Clinics, in their current form, are limited to providing primary curative healthcare. They have shown some success in this form. For example, users of Mohalla Clinics who previously used government facilities, save on an average two hours and 19 minutes of their time in using primary health care services. About $10 \%$ of the users were citizens who admitted to practising self-medication previously but are now getting proper healthcare at the Mohalla Clinics. Thus the Mohalla Clinic is a positive step towards universal primary health coverage and for many ordinary citizens, it has successfully bridged the gap in accessing primary healthcare in the current system. However, there is no community participation, whether in the planning of healthcare programmes, the monitoring and evaluation of clinics, the implementation of programmes or the execution of any activities. These are all organised top-down. Top-down interventions have failed to be effective in finding sites or locations for the clinics and organising community-friendly opening hours. It is also regrettable that Mohalla Clinics are not managed by Mohalla Sabhas, but by the JSS, and that power struggles between political parties are played out within local government bodies, subverting their important local governance roles.

This paper therefore proposes greater community participation in the evaluation of Mohalla Clinics, the shifting of resources away from MCD run (non-Mohalla) clinics to GoNCT-D administered Mohalla 
Clinics and the decentralisation of site selection for Mohalla Clinics to MCDs as ways in which to improve the functioning of Mohalla Clinics.

\section{Declaration of conflicting interest}

The authors declared no potential conflicts of interest with respect to the research, authorship, and/or publication of this article.

\section{Funding}

The authors received no financial support for the research, authorship, and/or publication of this article.

\section{References}

Aam Admi Party. (AAP) (2015) Aam Aadmi Party manifesto Delhi dialogue. Delhi: Aam Aadmi Party.

Arnstein, S.R. (1969) A ladder of citizen participation. Journal of the American Institute of Planners, 35 (4), 216-224. https://doi.org/10.1080/01944366908977225

Asian News International. (2020) 2 doctors teams conduct COVID-19 testing In Delhi's Azadpur Mandi. NDTV 1 May 2020. Available at: https://www.ndtv.com/delhi-news/coronavirus-india-2-doctors-teams-conductcovid-19-testing-in-delhi-azadpur-mandi-2221823 [Acessed 20 May 2020].

Babu, N.M. (2020) COVID-19 staff unable to reach 150 mohalla clinics shut in Delhi. The Hindu 27 March 2020. Available at: https://www.thehindu.com/news/cities/Delhi/coronavirus-staff-unable-to-reach-150mohalla-clinics-shut-in-delhi/article31284197.ece [Acessed 20 May 2020].

Bedi, A. and Sirur, S. (2020) 'We're no different from AIIMS, RML doctors' - Delhi mohalla clinic staff demand Covid insurance. The Print 06 December 2020. Available at: https://theprint.in/india/were-nodifferent-from-aiims-rml-doctors-delhi-mohalla-clinic-staff-demand-covid-insurance/561495/ [Accessed 16 December 2020].

Bhaduri, S.D. (2020) Delhi elections 2020: The success of mohalla clinics. Telegraph India 9 March 2020. Available at: https://www.telegraphindia.com/opinion/delhi-assembly-elections-2020-the-success-ofmohalla-clinics/cid/1752383 [Accessed 20 May 2020].

Bhatnagar, G.V. (2016) Congress report alleges irregularities in AAP's Mohalla Clinics project. The Wire 23 September 2016. Available at: https://thewire.in/politics/congress-aap-mohalla-clinics [Accessed 05 March 2019]

Choguill, M.B.G. (1996) A ladder of community participation for underdeveloped countries. Habitat International, 20 (3), 431-444. https://doi.org/10.1016/0197-3975(96)00020-3

Cornwall, A. (2002) Making spaces, changing places: situating participation in development. IDS Working Paper Series 170. Brighton: Institute of Development Studies.

Delhi Development Authority. (DDA) (2007) Master plan Delhi 2021. New Delhi: Delhi Development Authority.

Dutt, A. and Chitlangia, R. (2020) In times of Covid-19, mohalla clinics, small hospitals take lead in treating other illnesses. Hindustan Times 30 April 2020. Available at: https://www.hindustantimes.com/delhinews/in-times-of-covid-19-mohalla-clinics-small-hospitals-take-lead-in-treating-other-illnesses/storyvdjilQYPfZcSEpAoxRIDDO.html [Accessed 20 May 2020].

Gaventa, J. (2006) Finding the spaces for change: A power analysis. IDS Bulletin, 37 (6), 23-33. https://doi.org/10.1111/j.1759-5436.2006.tb00320.x

Ghosh, S. (2020) More and more 'corona warriors' falling prey to COVID-19 in New Delhi. The New Indian Express 4 May 2020. Available at: https://www.newindianexpress.com/cities/delhi/2020/may/04/moreand-more-corona-warriors-falling-prey-to-covid-19-in-new-delhi-2138942.html [Accessed 20 May 2020]

Goodwin, M. and Painter, J. (1996) Local governance, the crises of Fordism and the changing geographies of regulation. Transactions of the Institute of British Geographers, 21, 635-648.

https://doi.org/10.2307/622391 
Government of National Capital Territory of Delhi. (GoNCT-D) (2011) The Delhi Municipal Corporation (Amendment) Act, 2011. Delhi.

Government of National Capital Territory of Delhi. (GoNCT-D) (2015) Setting up of 100 Aam Aadmi Mohalla Clinics. New Delhi: Health and Family Welfare, D.O.

Government of National Capital Territory of Delhi. (GoNCT-D) (2016) Principals of delimitation. New Delhi: State Election Commission 4 May 2016. Available at:

http://sec.delhigovt.nic.in/wps/wcm/connect/doit_dsec/Delhi+State+Election+Commission/Home/Delimi tation+2016/Delimitation+2016\%28Draft\%29/Principles\%20of\%20Delimitation [Accessed 30 December 2020].

Government of National Capital Territory of Delhi. (GoNCT-D) (2017a) Brief write up on Aam Aadmi mohalla clinic. Available at:

http://web.delhi.gov.in/wps/wcm/connect/doit_health/Health/Home/Directorate+General+of+Health+Ser vices/Aam+Aadmi+Mohalla+Clinics [Accessed 15 December 2020].

Government of National Capital Territory of Delhi. (GoNCT-D) (2017b) Be a proud volunteer of Aam Aadmi Mohalla Clinic. New Delhi: Government of NCT, Delhi.

Government of National Capital Territory of Delhi. (GoNCT-D) (2018) Proposal for setting up of Rogi Kalyan Samiti. New Delhi: Government of NCT, Delhi

Government of National Capital Territory of Delhi. (GoNCT-D) (n.d.) Mohalla Sabha website. Available at: http://mohallasabha.delhi.gov.in/ [Accessed 5 April 2019].

Hickey, S. and Mohan, G. (2004) Participation - from tyranny to transformation?: Exploring new approaches to participation in development. London: Zed books.

International Institute for Population Sciences (IIPS) and ICF (2017) National family health survey (NFHS-4), 2015-16. Mumbai, India: IIPS.

Kundu, D. (2011) Elite capture in participatory urban governance. Economic and Political Weekly, 46 (10), 2325.

Lahariya, C. (2017) Mohalla clinics of Delhi, India: Could these become platform to strengthen primary healthcare? Journal of Family Medicine and Primary Care, 6 (1), 1-33. https://doi.org/10.4103/jfmpc.jfmpc_29_17

Ministry of Health and Family Welfare. (2013) National urban health mission - framework for implementation. New Delhi: Govt. of India.

Mohanty, A. (2014) From Bhagidari to Mohalla Sabhas in Delhi: When participation trumps governance. Economic and Political Weekly, 49 (14), 16-18.

Nundy, M. (2005) Primary healthcare in India: Review of policy, plan and committee reports. National Commission on Macroeconomics and Health. Financing and Delivery of Health Care Services. (pp. 3942). New Delhi: Govt. of India.

Olum, Y. (2014) Decentralisation in developing countries: Preconditions for successful implementation. Commonwealth Journal of Local Governance (15), 23-38. https://doi.org/10.5130/cjlg.v0i0.4061

Patel, S., Sliuzas, R., Georgiadou, Y. and Mathur, N. (2016a) Socio-spatial order of neoliberal Ahmedabad. The Netherlands: University of Twente Faculty of Geo-Information and Earth Observation (ITC).

Patel, S., Sliuzas, R. and Georgiadou, Y. (2016b) Participatory local governance in Asian cities: Invited, closed or claimed spaces for urban poor? Environment and Urbanization Asia, 7 (1), 1-21. https://doi.org/10.1177/0975425315619044

Press Trust of India. (2020) COVID-19: Have enough infra to vaccinate Delhi's entire population in few weeks, says Jain. The Hindu 27 November 2020. Available at: https://www.thehindu.com/news/cities/Delhi/covid-19-have-enough-infra-to-vaccinate-delhis-entirepopulation-in-few-weeks-says-jain/article33193303.ece\# [Accesed 15 December 2020].

Purcell, M. (2003) Citizenship and the right to the global city: Reimagining the capitalist world order. International Journal of Urban and Regional Research, 27, 564-590. https://doi.org/10.1111/14682427.00467 
Rao, K.V. (2016) Delhi's Mohalla Sabha: Participation and party-building. Master of Arts, Tata Institute of Social Sciences. Mumbai.

Registrar General and Census Commissioner of India. (2011) Primary census abstract. New Delhi: Govt. of India.

Rifkin, S.B. (1986) Lessons from community participation in health programmes. Health Policy and Planning, 1 (3), 240-249. https://doi.org/10.1093/heapol/1.3.240

Rifkin, S.B. (1996) Paradigms lost: toward a new understanding of community participation in health programmes. Acta Tropica, 61 (2), 79-92. https://doi.org/10.1016/0001-706x(95)00105-n

Sheikh, S. and Banda S. (2015) The intersection of governments in Delhi. Cities of Delhi. New Delhi: Centre for Policy Research.

Sundararaman, T., Mukhopadhyay, I. and Muraleedharan, V. (2016) No respite for public health. Economic \& Political Weekly, 51 (16), 39-42.

The Statesman (2020) Another Mohalla Clinic doctor in Delhi tests positive for Coronavirus, second in a week. 31 March 2020. Available at: https:/www.thestatesman.com/india/another-delhi-mohalla-clinic-doctortests-positive-coronavirus-second-week-1502872223.html [Accessed 20 May 2020].

Times Now News (2020) Major coronavirus scare in Delhi: Mohalla Clinic doctor, wife, daughter test positive; 800 people quarantined. 26 March 2020. Available at: https://www.timesnownews.com/delhi/article/major-coronavirus-scare-in-delhi-mohalla-clinic-doctorwife-daughter-test-positive-800-people-quarantined/569620 [Accessed 20 May 2020].

VeneKlasen, L., Miller, V., Budlender, D. and Clark, C. (2002) A new weave of power, people \& politics: The action guide for advocacy and citizen participation. Oklahoma City: World Neighbors.

Verbeek, T. (2014) Reconnecting urban planning and public health: An exploration of a more adaptive approach. Proceedings of Annual Congress: From control to co-evolution (AESOP-2014). Utrecht, The Netherlands.

World Health Organization. (WHO) (1978) Declaration of Alma-Ata. International Conference on Primary Health Care, 6-12 September 1978. Kazakhstan: WHO.

World Health Organization. (WHO) (2010) Why urban health matters. Geneva: World Health Organization.

World Health Organization (WHO) ( n.d.) World Health Organization global health expenditure. Available at: https://data.worldbank.org/indicator/SH.XPD.CHEX.GD.ZS [Retrieved March 2019]. 